\title{
VEGF ameliorates pulmonary hypertension through inhibition of endothelial apoptosis in experimental lung fibrosis in rats
}

\author{
Laszlo Farkas, 1,2,3 Daniela Farkas,, 1,2,3 Kjetil Ask,1,2 Antje Möller,1,2,4 \\ Jack Gauldie, ${ }^{2}$ Peter Margetts, ${ }^{1,2}$ Mark Inman, ${ }^{1}$ and Martin Kolb 1,2,4

\begin{abstract}
${ }^{1}$ Department of Medicine, McMaster University, Firestone Institute for Respiratory Health and St. Joseph's Healthcare, and 2Department of Pathology and Molecular Medicine, McMaster University, Hamilton, Ontario, Canada. ${ }^{3 M e d i z i n i s c h e ~ K l i n i k ~ I I, ~}$ Universität Regensburg, Regensburg, Germany. ${ }^{4}$ Medizinische Klinik, Julius-Maximilian-Universität Würzburg, Würzburg, Germany.
\end{abstract}

\begin{abstract}
Idiopathic pulmonary fibrosis (IPF) can lead to the development of secondary pulmonary hypertension (PH) and ultimately death. Despite this known association, the precise mechanism of disease remains unknown. Using a rat model of IPF, we explored the role of the proangiogenic and antiapoptotic growth factor VEGF in the vascular remodeling that underlies $\mathrm{PH}$. In this model, adenoviral delivery of active TGF- $\beta 1$ induces pulmonary arterial remodeling, loss of the microvasculature in fibrotic areas, and increased pulmonary arterial pressure (PAP). Immunohistochemistry and mRNA analysis revealed decreased levels of VEGF and its receptor, which were inversely correlated with PAP and endothelial cell apoptosis in both the micro- and macrovasculature. Treatment of IPF rats with adenoviral delivery of VEGF resulted in reduced endothelial apoptosis, increased vascularization, and improved PAP due to reduced remodeling but worsened PF. These data show that experimental pulmonary fibrosis (PF) leads to loss of the microvasculature through increased apoptosis and to remodeling of the pulmonary arteries, with both processes resulting in PH. As administration of VEGF ameliorated the PH in this model but concomitantly aggravated the fibrogenic process, VEGF-based therapies should be used with caution.
\end{abstract}

\section{Introduction}

Idiopathic pulmonary fibrosis (IPF) is a chronic lung disease of unclear cause and poor prognosis (1-3). Advanced IPF is frequently associated with pulmonary hypertension $(\mathrm{PH})$, characterized by an increase in mean pulmonary arterial pressure (mPAP) (4-6). The development of PH correlates with the prognosis of IPF patients (6-8). Hypoxic vasoconstriction and loss of pulmonary capillaries are thought to be major contributing factors for the pathogenesis of PH in IPF (9), but the detailed mechanism and time course are unclear. The complex biological processes leading to pulmonary fibrosis (PF) could be directly involved in the pathogenesis of vascular remodeling (4).

Vessel density is not uniform in IPF lungs: it is reduced within fibrotic areas, while it is increased in the surrounding nonfibrotic tissue (10-12). The net effect of these changes is a reduction in cross-sectional vascular area. Recent studies suggest that the loss of vessels is not merely due to accumulating scar tissue but may be the result of an imbalance between angiogenic and angiostatic factors. It has been demonstrated that angiogenic factors such as VEGF or IL-8 are decreased in IPF lungs, thought to be a TGF- $\beta 1$ rich microenvironment, while angiostatic molecules such as pigment epithelium-derived factor (PEDF) are increased $(10,11)$. In

Conflict of interest: The authors have declared that no conflict of interest exists.

Nonstandard abbreviations used: AdDL70, adenovector without insert; AdTGF- $\beta 1$, adenovector with a mutant TGF- $\beta 1$ gene; AdVEGF, adenovector with the 165 -aminoacid variant of the human VEGF gene; BALF, bronchoalveolar lavage fluid; ED, external diameter; IHC, immunohistochemistry; IPF, idiopathic pulmonary fibrosis; mPAP, mean PAP; MWT, medial wall thickness; P-, phospho; PA, pulmonary artery; PAI-1, plasminogen-activator inhibitor-1; PAP, pulmonary arterial pressure; PEDF, pigment epithelium-derived factor; $\mathrm{PF}$, pulmonary fibrosis; $\mathrm{PH}$, pulmonary hypertension; PSR, picro-sirius red; TCA, tissue-covered area; VAR, vessel/area ratio. Citation for this article: J. Clin. Invest. 119:1298-1311 (2009). doi:10.1172/JCI36136 apparent contrast, other studies showed that VEGF expression can be stimulated in PF via TGF- $\beta 1$, and it has also been suggested that VEGF may enhance PF, possibly through induction of angiogenesis (13-15).

VEGF is a mitogenic and survival factor for ECs in the lung and influences functional properties including $\mathrm{NO}$ and prostacyclin synthesis (16). VEGF transcription is mainly induced by HIF-1 $\alpha$, which accumulates in the cells under hypoxia, but is also regulated by TGF- $\beta 1$ $(17,18)$. Signaling through VEGFR2 is responsible for important maintenance and survival functions of VEGF, and inhibition of VEGF has been implicated in EC apoptosis and the development of PH and emphysema (16). The detailed function of PEDF is yet unknown, but it clearly is strongly angiostatic and inhibits VEGFinduced angiogenesis on different levels $(19,20)$.

It appears reasonable to find that not only PF progression but also angiogenesis is heterogeneous and patchy in a chronic disease such as IPF, both in a temporal and spatial manner. This would explain some of the contradictory findings in previous studies. Although angiogenesis is believed to be involved in the development of PF and PH, there are a lack of mechanistic studies investigating the relationship among PF, angiogenesis, and PH (4). Our aim was to investigate the role of angiogenesis and the contribution of pro- and antiangiogenic factors to secondary $\mathrm{PH}$ and the progression of PF in an experimental model. We demonstrated decreased VEGF levels, apoptosis of microvascular and pulmonary artery (PA) ECs, loss of microvascularization, and thickening of the PA media with increasing degrees of PF. Furthermore, we found a negative correlation between VEGF and mPAP. Concomitant overexpression of VEGF and TGF- $\beta 1$ reduced apoptosis of ECs and improved $\mathrm{PH}$, suggesting a link between inhibition of VEGF-induced angiogenesis during fibrogenesis and the development of $\mathrm{PH}$. 

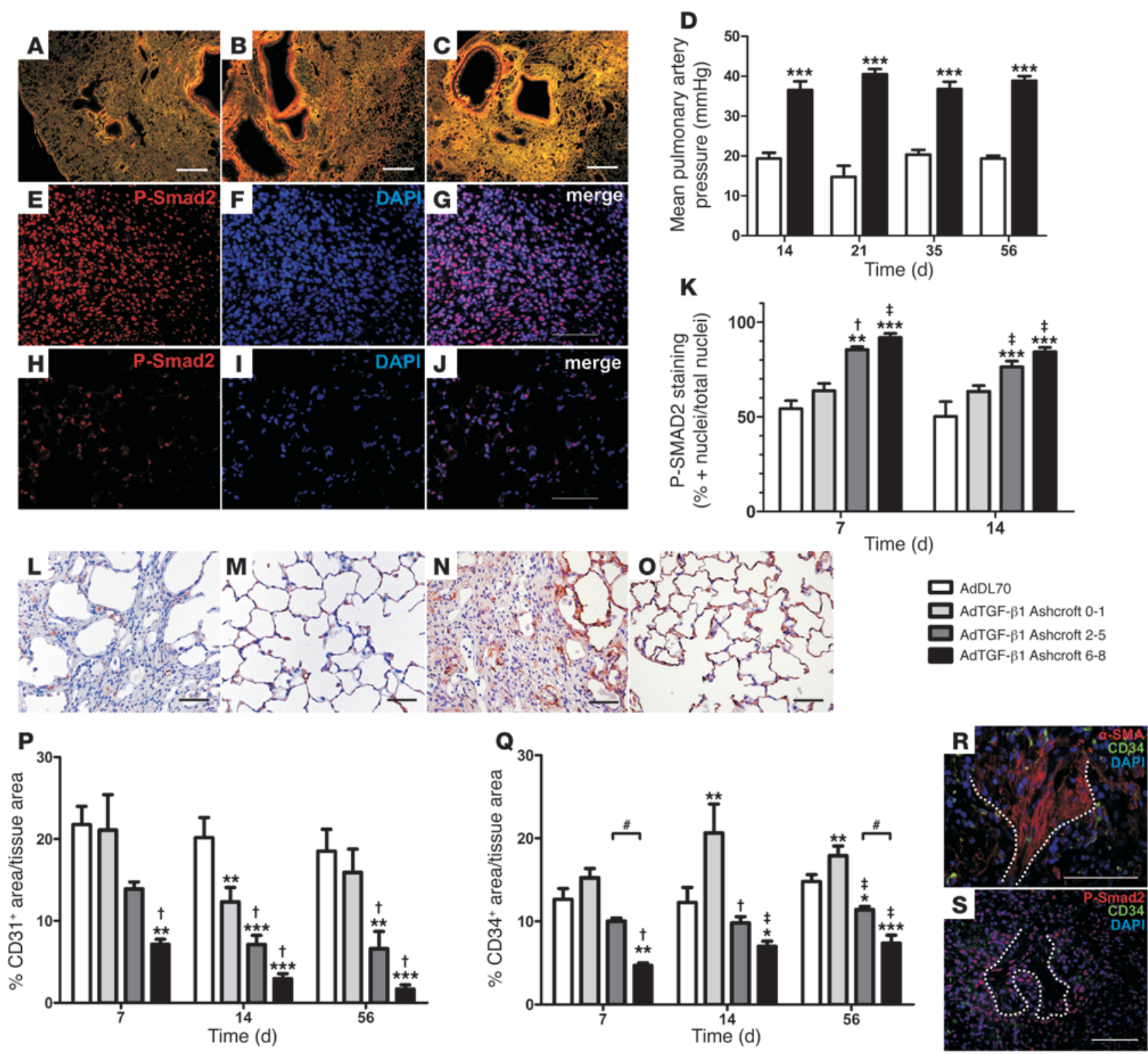

Figure 1

PF, PH, TGF- $\beta$ signaling, and vascular density in AdTGF- $\beta 1$-induced PF. (A-C) PSR-stained sections from AdTGF- $\beta 1$ rats at days 14 (A), 21 (B), and 56 (C) (dark field, polarized light). (D) mPAP after AdTGF- $\beta 1$. White bars, AdDL70; black bars, AdTGF- $\beta 1$. (E-J) Representative images for P-Smad2 (red) at day 7 in AdTGF- $\beta 1$-treated (E-G) and AdDL70-treated animals $(\mathbf{H}-\mathbf{J})$. (K) Percentage of P-Smad2-positive versus total nuclei in lung parenchyma categorized according to PF degree. (L-O) Representative IHC for CD31 (L and $\mathbf{M})$ and $C D 34(\mathbf{N}$ and $\mathbf{O})$ in regions with severe PF after AdTGF- $\beta 1$ ( $\mathbf{L}$ and $\mathbf{N}$ ) compared with AdDL70 (M and $\mathbf{O}$ ) administration. All day 56. (P and $\mathbf{Q})$ Percentage of CD31+ (P) and $\mathrm{CD}_{34}{ }^{+}(\mathbf{Q})$ area versus tissue area in lung parenchyma categorized according to PF degree. (R and $\left.\mathbf{S}\right)$ CD34 staining is absent in $\alpha-S M A^{+}$ fibroblastic foci (dotted line) (R) and decreased in areas of high nuclear P-Smad2 immunoreactivity (red) (dotted line: fibroblastic focus) (S). Original magnification, $\times 25(\mathbf{A}-\mathbf{C}) ; \times 400(\mathbf{E}-\mathbf{J}, \mathbf{L}-\mathbf{O}$, and $\mathbf{S}) ; \times 630(\mathbf{R})$. Scale bars: $500 \mu \mathrm{m}(\mathbf{A}-\mathbf{C}) ; 50 \mu \mathrm{m}(\mathbf{G}, \mathbf{J}, \mathbf{L}-\mathbf{0}, \mathbf{R}$, and $\mathbf{S})$. Each bar shows mean \pm SEM of 3-4 animals per group $(\mathbf{K})$ and $4-6$ animals per group (D, $\mathbf{P}$, and $\mathbf{Q}$ ). ${ }^{*} P<0.05 ;{ }^{* *} P<0.01$; ${ }^{* * *} P<0.0001$ (all versus AdDL70); ${ }^{\dagger} P<0.05 ; \ddagger P<0.01$ (both versus Ashcroft $0-1$ ); ${ }^{*} P<0.05$ (1-way ANOVA).

\section{Results}

$P F$ and $P H$ in AdTGF- $\beta 1-$ induced PF. PF developed after adenovector with a mutant TGF- $\beta 1$ gene (AdTGF- $\beta 1$ ) similarly to the way it developed in previous studies (Figure 1, A-C) (21). Right heart catheterization started showing increased mPAP in AdTGF- $\beta 1$ rats by day 14 and continued until day 56 (Figure 1D). There were no differences between adenovector without insert (AdDL70) and naive animals.
$P$-Smad 2 and vascular density in AdTGF- $\beta 1$-induced PF. The percentage of cells positive for nuclear phospho-Smad2 (P-Smad2) was higher, with increasing degrees of PF in AdTGF- $\beta 1$ animals at day 7 and 14 after adenovirus administration (Figure 1, E-K).

From day 7, numbers of $\mathrm{CD} 31^{+}$and $\mathrm{CD} 34^{+}$cells, which represent endothelial cells and thereby local microvasculature, were diminished in AdTGF- $\beta 1$ animals, especially in areas of severe PF (Figure 1, 

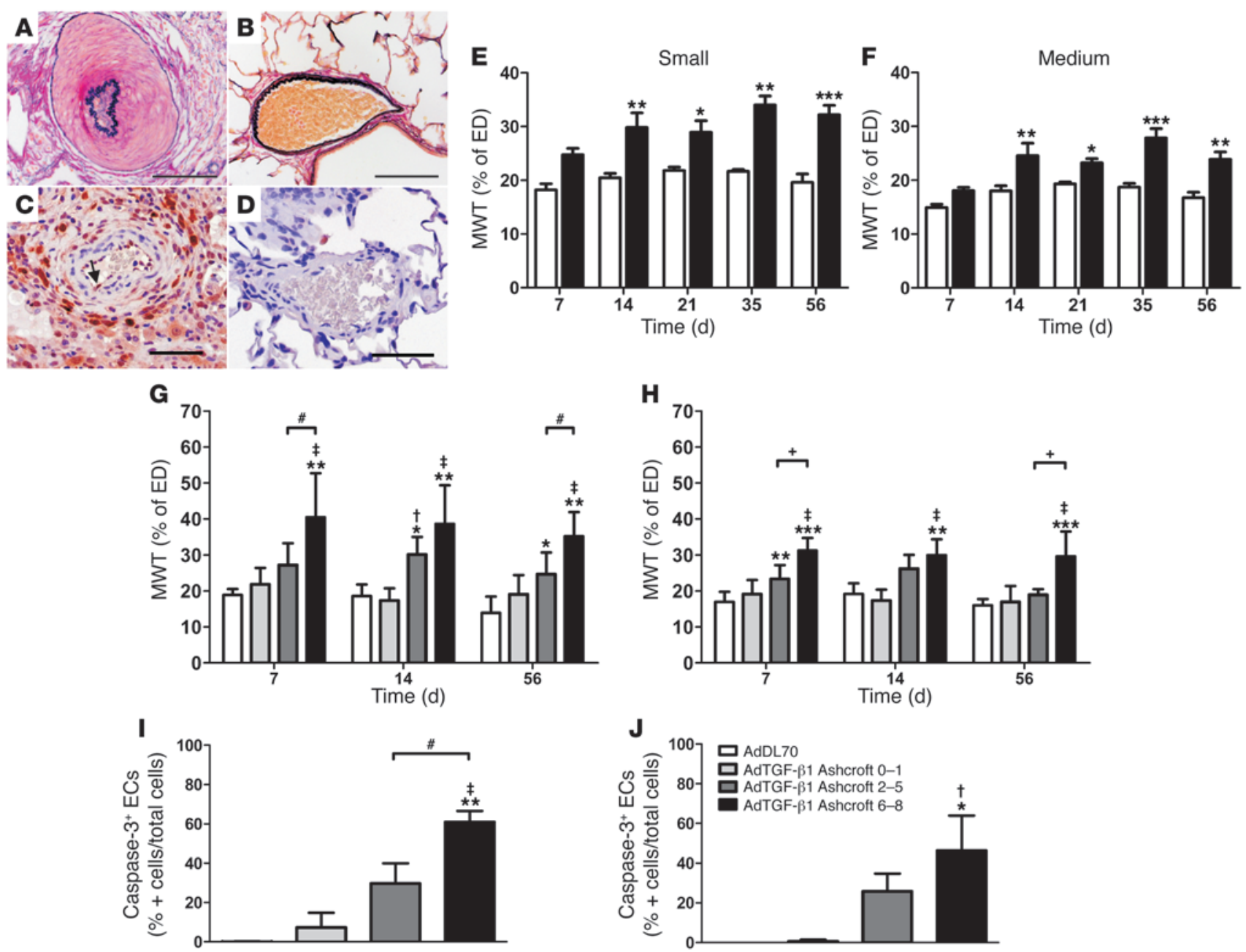

\section{Figure 2}

Vascular remodeling and PA EC apoptosis in AdTGF- $\beta 1$-induced PF. (A and B) Medium-sized PA from AdTGF- $\beta 1$ (A) and AdDL70 (B) rat, day 21. (C and D) Representative PA with caspase-3-positive EC (arrow) after AdTGF- $\beta 1$ administration, day 7 (C), no caspase-3 immunoreactivity in PA after AdDL70 (D). Magnification, $\times 400$. Scale bars: $50 \mu \mathrm{m}$. Vessels categorized according to ED: small, $<50 \mu \mathrm{m}$ (E, G, and I); medium, $50 \mu \mathrm{m} \leq \mathrm{ED}<100 \mu \mathrm{m}(\mathbf{F}, \mathbf{H}$, and $\mathbf{J})$. (E and $\mathbf{F})$ Relative MWT of AdTGF- $\beta 1$-induced PF (black bars). White bars, AdDL70. (G and $\mathbf{H})$ Relative MWT of small (G) and medium (H) PA categorized according to PF degree. (I and J) Percentage of caspase-3-positive PA ECs in small (I) and medium (J) PA of AdTGF- $\beta 1$ animals at day 7 categorized according to PF degree. Data were confirmed by IHC for cleaved caspase-3 (not shown). Each bar shows mean \pm SEM of 3-4 animals per group (I and $\mathbf{J})$ or $4-6$ animals per group $(\mathbf{E}-\mathbf{H}) .{ }^{*} P<0.05 ;{ }^{* *} P<0.01 ;{ }^{* * *} P<0.0001$ (all versus AdDL70); ${ }^{\dagger} P<0.05 ; \neq P<0.01$ (both versus Ashcroft 0 -1); ${ }^{\sharp} P<0.05 ;{ }^{+} P<0.01$ (1-way ANOVA).

L-Q). Fibrotic score and vascular density were inversely correlated (percentage of $\mathrm{CD} 31^{+}$and percentage of $\mathrm{CD} 34^{+}$area of tissue area) (Spearman rank: $r=-0.6930, P<0.0001$ for CD31; $r=-0.8528$, $P<0.0001$ for CD34). Interestingly, we found an increase in CD34 ${ }^{+}$ area in nonfibrotic sections of AdTGF- $\beta 1$ animals (Ashcroft $0-1$; see Methods) compared with AdDL70 as early as day 7 (Figure 1Q). No differences were seen between naive and AdDL70 rats. Double immunofluorescence revealed absence of $\mathrm{CD} 34^{+}$within $\alpha-\mathrm{SMA}^{+}$ fibroblastic foci as well as reduced $\mathrm{CD} 34^{+}$vascularization in areas of high P-Smad2 immunoreactivity (Figure 1, R and S). Similarly, we noted a reduction of vessel/area ratio (VAR) for macrovasculature, with increasing degree of PF in AdTGF- $\beta 1$ animals (day 14): VAR was $5.018 \pm 1.142$ vessels $/ \mathrm{mm}^{2}$ tissue-covered area (TCA) for Ashcroft 6-8 vs. $9.568 \pm 0.2273$ vessels $/ \mathrm{mm}^{2}$ TCA for Ashcroft $0-1$. The overall VAR was reduced for AdTGF- $\beta 1$ animals versus
AdDL70 animals (7.213 \pm 0.531 vs. $10.12 \pm 1.115$ vessels $/ \mathrm{mm}^{2}$ TCA; average reduction: $28.73 \%)$. Small vessels $(25<\mathrm{ED}<50 \mu \mathrm{m}$, where ED indicates external diameter) were mostly affected, with VAR of $3.978 \pm 0.434$ vessels $/ \mathrm{mm}^{2}$ TCA for AdTGF- $\beta 1$ versus $6.600 \pm 0.73$ vessels $/ \mathrm{mm}^{2}$ for AdDL70 (average reduction: $39.73 \%$ ).

EC apoptosis and remodeling of pulmonary arteries in AdTGF- $\beta 1$-induced $P F$. Vascular remodeling, assessed by medial wall thickness (MWT), was increased by day 14 after AdTGF- $\beta 1$ administration for small and medium PA (Figure 2, A, B, E, and F; ED: small: < $50 \mu \mathrm{m}$; medium: $50 \mu \mathrm{m} \leq \mathrm{ED}<100 \mu \mathrm{m})$. There were no differences between AdDL70 and naive animals (small: $17.97 \% \pm 1.48 \%$; medium: $17.72 \% \pm 1.54 \%$ ).

Examination of PA correlated to the degree of PF in surrounding tissue showed an increase of MWT of small and medium PA in more fibrotic tissue (equal to increasing Ashcroft score) after day 7 (Figure 2, G and H). P-Smad2 in PA smooth muscle cells was 


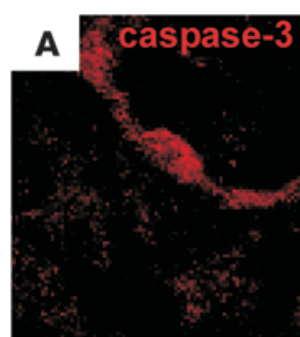

F

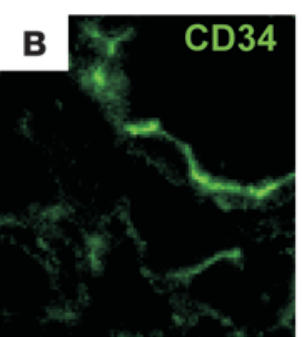

H

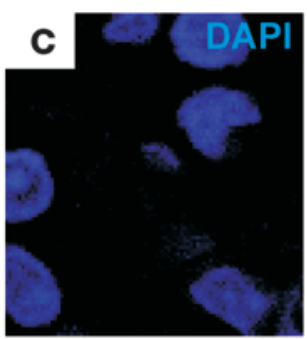

I

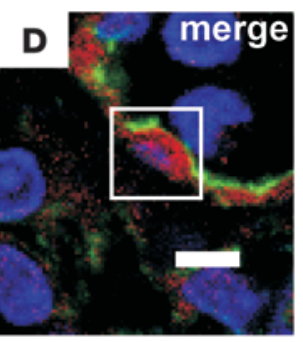

J
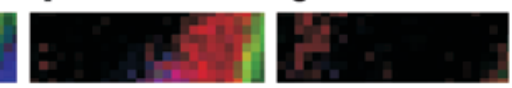
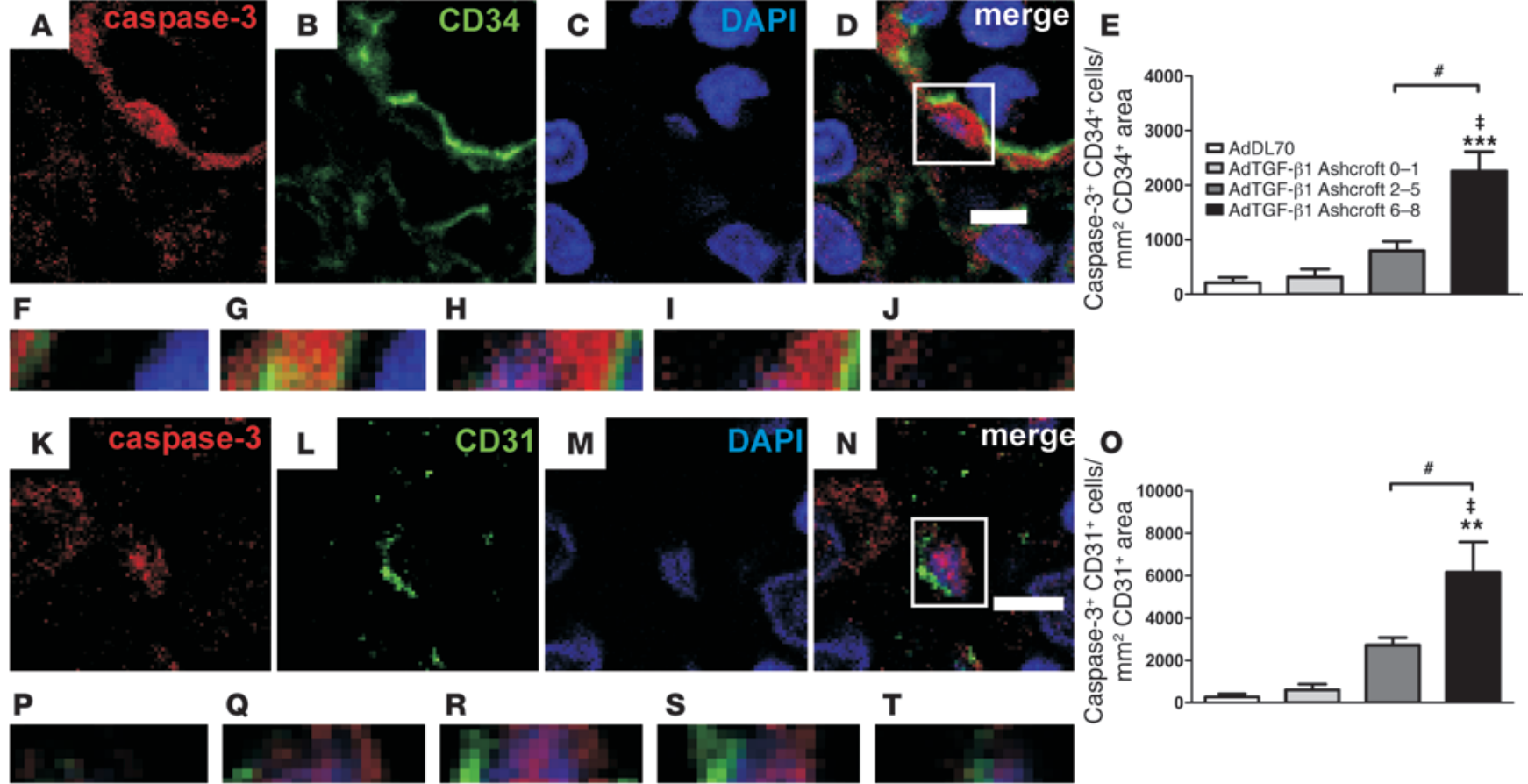

R

s

$\mathbf{T}$
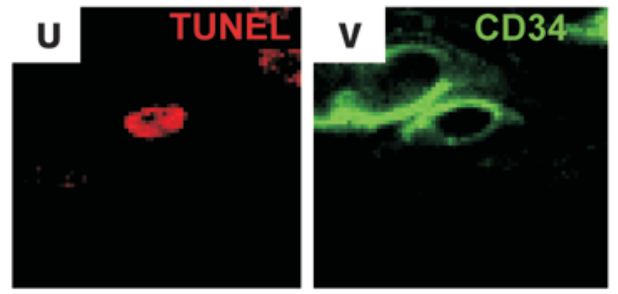

AA

\section{BB}

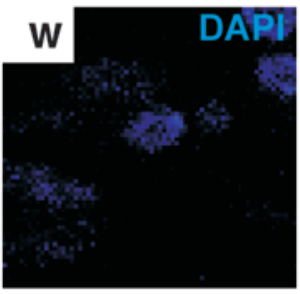

CC

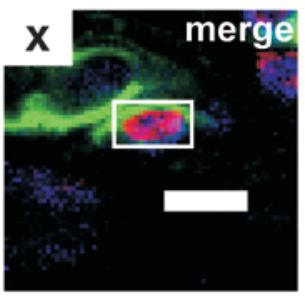

DD
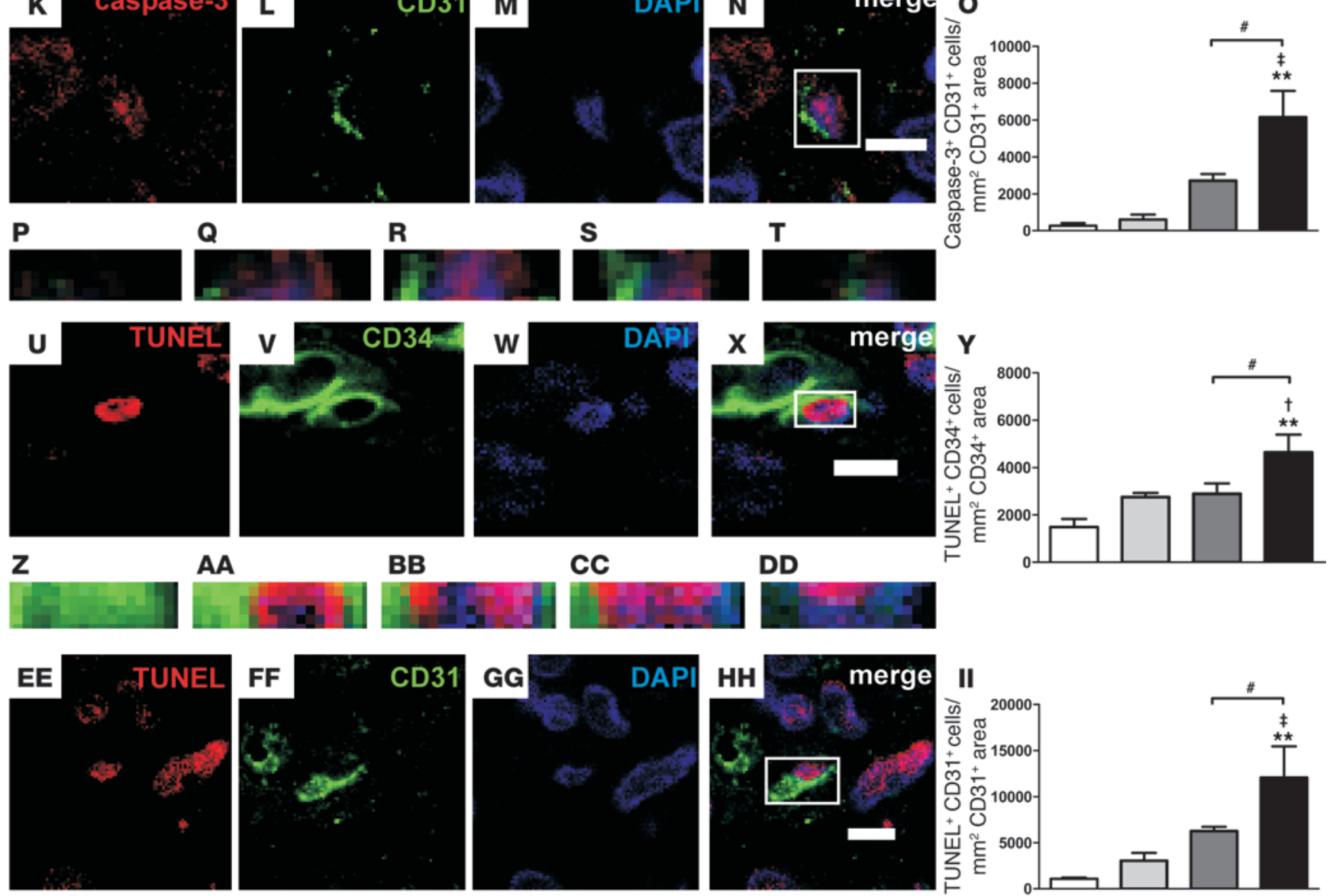

KK

LL
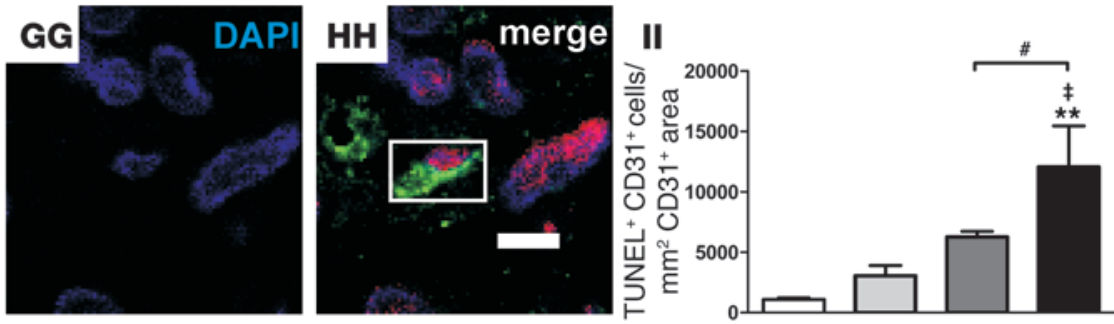

JJ

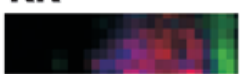

MM

NN

\section{Figure 3}

Microvascular EC apoptosis in AdTGF- $\beta 1$ PF at day 7. Representative optical sections acquired by confocal microscopy for caspase-3/CD34 (A-J), caspase-3/CD31 (K-T), TUNEL/CD34 (U-DD), and TUNEL/CD31 (EE-NN) immunofluorescence showing apoptotic microvascular EC. Additional images (F-J, P-T, Z-DD, and $\mathbf{J} \mathbf{J}-\mathbf{N N}$ ) demonstrate reconstructed sections in z-direction through the digital image stack in equal intervals from the top to the bottom of the white box presented in images $\mathbf{D}, \mathbf{N}, \mathbf{X}$, and $\mathbf{H H}$, indicating that the demonstrated cell is positive. Original magnification, $\times 630$. Scale bars: $5 \mu \mathrm{m}$. Quantification of cells double positive for caspase-3/CD34 (E), caspase-3/CD31 (O), TUNEL/CD34 (Y), and TUNEL/CD31 (II) categorized according to PF degree. Values shown indicate number of double stained cells per $\mathrm{mm}^{2} \mathrm{CD} 31^{+}(\mathbf{O}, \mathrm{II})$ or $\mathrm{CD}_{4}+(\mathrm{E}, \mathrm{Y})$ area. Each bar shows mean \pm SEM of 3-4 animals per group. ${ }^{* *} P<0.01 ;{ }^{* \star *} P<0.0001$ (all versus AdDL70); $† P<0.05 ; \ddagger P<0.01$ (both versus AdTGF- $\beta 1$ Ashcroft $0-1) ; \# P<0.05$ (1-way ANOVA). 

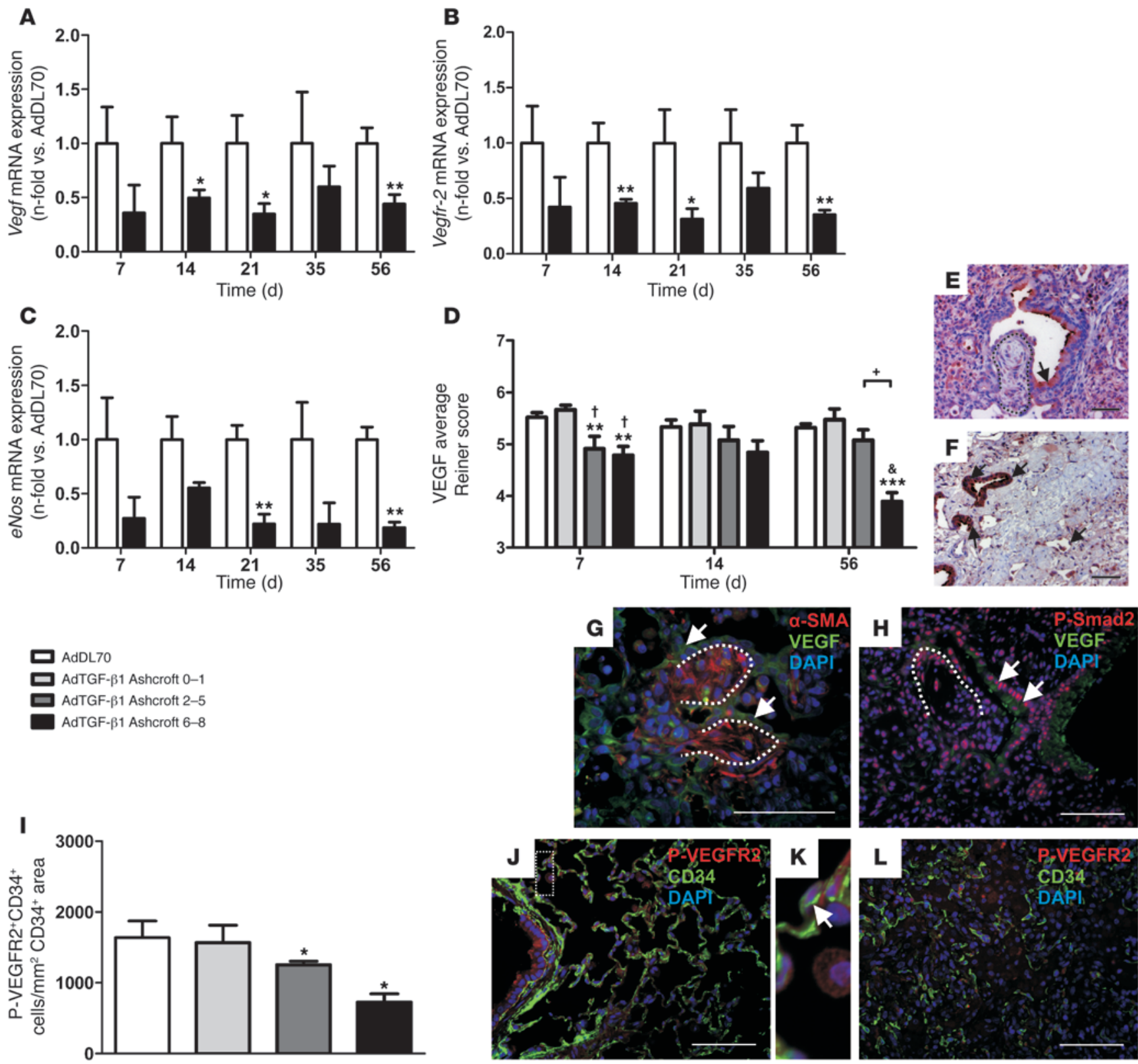

Figure 4

VEGF expression and localization in AdTGF- $\beta 1$ PF. (A-C) Relative mRNA levels of Vegf (A), Vegfr-2 (B), and eNos (C) in AdTGF- $\beta 1$ rats (black bars) normalized to AdDL70 (white bars). (D) Semiquantitative analysis of VEGF in alveolar walls and fibrotic interstitium according to PF degree. VEGF immunoreactivity (brown in $\mathbf{E}$ and $\mathbf{F}$; green in $\mathbf{G}$ and $\mathbf{H}$ ) was decreased in fibroblastic foci (dotted line in $\mathbf{E}, \mathbf{G}$, and $\mathbf{H}$ ) by day 14 and absent in fibrotic scars at day $56(\mathbf{F})$. VEGF was present in epithelial cells (arrows in $\mathbf{E}-\mathbf{H}$ ) and decreased in areas of high nuclear P-Smad2 immunoreactivity (H). (I) Quantification of endothelial VEGFR2 phosphorylation at day 7 according to PF degree. Values shown represent P-VEGFR2+CD34+ cells $/ \mathrm{mm}^{2}$ CD34+ area. (J-L) Representative images of P-VEGFR2 and CD34 double immunofluorescence from AdDL70 (J and K) and AdTGF- $\beta 1$ (L). (K) Double-positive cell (arrow) enlarged from $\mathbf{J}$ (dotted rectangle). Shown are AdDL70 at day 7 (J and K) and AdTGF- $\beta 1$ at day 7 (L), day $14(\mathbf{E}, \mathbf{G}$, and $\mathbf{H})$, and day $56(\mathbf{F})$. Original magnification, $\times 400(\mathbf{E}, \mathbf{F}, \mathbf{H}$, and $\mathbf{J}-\mathbf{L}) ; \times 630(\mathbf{G})$. Scale bars: $50 \mu \mathrm{m}$. Each bar represents mean \pm SEM of 4-6 animals per group (A-D) and 3-4 animals per group (I). ${ }^{\star} P<0.05 ;{ }^{\star \star} P<0.01 ;{ }^{\star \star \star} P<0.0001$ (all versus AdDL70); ${ }^{\dagger} P<0.05 ;{ }^{\&} P<0.0001$ (both versus AdTGF- $\beta 1$ Ashcroft $0-1) ;{ }^{+} P<0.01$, by Student's $t$ test $(\mathbf{A}-\mathbf{C})$ and 1 -way ANOVA (D and I).

not related to PF score (not shown). The percentage of caspase-3positive ECs was augmented in small and medium PA, with rising degrees of PF by day 7 (Figure 2, C, D, I, and J) and return to baseline by day 14 . These data were confirmed by immunohistochemistry (IHC) for cleaved caspase-3 (not shown).
Microvascular EC apoptosis. Increased apoptosis of $\mathrm{CD} 31^{+}$or $\mathrm{CD} 34^{+}$microvascular ECs was predominantly found in highly fibrotic areas at day 7, shown by caspase-3/CD31, caspase-3/ CD34, TUNEL/CD31, and TUNEL/CD34 immunofluorescence (Figure 3, E, O, Y, and II). This increase was not seen anymore 

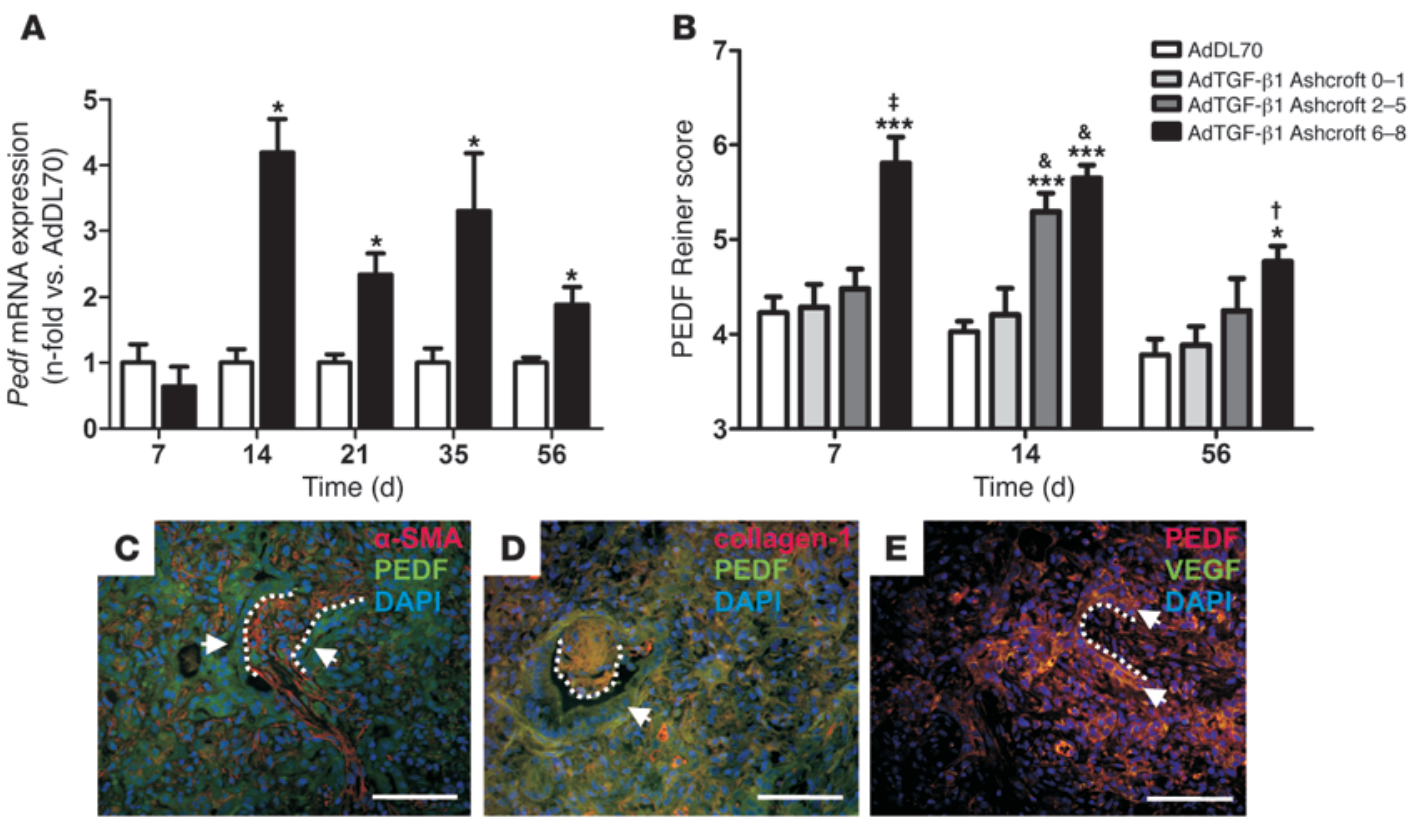

\section{Figure 5}

PEDF expression and immunolocalization. (A) Pedf mRNA in lung homogenate from AdTGF- $\beta 1$ (black bars) day 7 to day 56 , normalized to AdDL70 (white bars). Bars represent mean \pm SEM of $4-6$ animals per group. ${ }^{*} P<0.05$ versus AdDL70 (Student's $t$ test). (B) Semiquantitative analysis of PEDF IHC (days 7, 14, and 56) in parenchyma, according to PF degree. Each column represents mean \pm SEM of 4-6 animals per group. ${ }^{*} P<0.05 ;{ }^{* \star *} P<0.0001$ (both versus AdDL70); ${ }^{\dagger} P<0.05 ; \ddagger P<0.01$; and ${ }^{\circledR} P<0.0001$, each versus AdTGF- $\beta 1$ Ashcroft $0-1,1$-way ANOVA. (C and D) PEDF was found in fibroblastic foci (dotted lines) and fibrotic interstitium and colocalized with $\alpha$-SMA (C) and collagen-1 (D). PEDF was highly expressed in epithelial cells (arrows, C and D). (E) Areas of high PEDF staining, such as fibroblastic foci (dotted lines), were faintly stained with VEGF, while both colocalized in epithelial cells (arrows). Images C-E show day 14 after AdTGF- $\beta 1$ administration. Original magnification, $\times 400$. Scale bars: $50 \mu \mathrm{m}$.

by day 14. Confocal microscopy confirmed that individual cells were positive for both markers and represented apoptotic microvascular ECs (Figure 3, A-J, for caspase-3/CD34; Figure 3, K-T, for caspase-3/CD31; Figure 3, U-DD, for TUNEL/CD34; Figure 3, EE-NN, for TUNEL/CD31).

Vegf, Vegfr-2, and eNOS mRNA levels in lung homogenate. Vegf, Vegfr-2, and $e N O S$ mRNA were decreased until day 56 (Figure 4, A-C), with no difference between AdDL70 and naive rats. Relative mRNA levels of Vegf correlated negatively with mPAP for AdDL70 and AdTGF- $\beta 1$ (Spearman rank: $r=-0.5265, P=0.002$ ).

Spatiotemporal distribution of VEGF and VEGFR2 phosphorylation. VEGF was strongly positive in epithelial and endothelial cells, weak in fibroblasts and fibrotic interstitium, and almost absent within fibroblastic foci (Figure 4, E and G). VEGF was decreased in severely (Ashcroft 6-8) and moderately fibrotic areas (Ashcroft $2-5$ ) by day 7 (Figure 4D). In addition, VEGF was reduced when P-Smad2 staining was present (Figure $4 \mathrm{H})$. In advanced PF, interstitial VEGF was almost absent in severely fibrotic regions (Figure $4, \mathrm{D}$ and F). In contrast, strong VEGF was detected in epithelial cells in dense scars (Figure 4F).

Double immunofluorescence revealed VEGFR2 phosphorylation in airway epithelium and CD $34^{+}$microvascular ECs of AdDL70 (Figure 4 , J and $\mathrm{K}$ ). In contrast, the number of P-VEGFR2 ${ }^{+} \mathrm{CD} 34^{+}$cells was declining, with increasing PF after day 7 (Figure 4, I and L).

Pedf $m R N A$ expression and protein distribution. Pedf mRNA was increased from day 14 in AdTGF- $\beta 1$ lung homogenate, sustained until day 56 (Figure 5A). Expression of Pedf in AdDL70 was not different from that in naive rats. Relative mRNA lev- els of Pedf correlated positively with mPAP between day 14 and 56 for AdDL70 and AdTGF- $\beta 1$ (Spearman rank: $r=0.5053$, $P=0.002)$. PEDF was increased from day 7 in fibrotic interstitium and fibroblastic foci of severe (Ashcroft 6-8) fibrotic areas, followed by an additional rise in moderately fibrotic regions (Ashcroft 2-5) by day 14 (Figure 5B). PEDF was mainly localized to the cytoplasm of mesenchymal cells (in and around fibroblastic foci), epithelial, and endothelial cells (Figure 5, C-E). It colocalized with $\alpha$-SMA and collagen- 1 within fibroblastic foci and fibrotic interstitium (Figure 5, C and D). VEGF was almost absent in these areas, while it colocalized with PEDF in epithelial cells around fibroblastic foci (Figure 5E).

Characterization of concomitant AdTGF- $\beta 1 / A d V E G F$. Coadministration of AdTGF- $\beta 1$ and adenovector with the 165 -amino-acid variant of the human VEGF gene (AdVEGF) induced high levels of active TGF- $\beta 1$ and VEGF in the bronchoalveolar lavage fluid (BALF) at day 7, which was back to baseline by day 14 (Table 1). We found an additional increase in lung collagen in AdTGF- $\beta 1 /$ AdVEGF animals versus AdTGF- $\beta 1 /$ AdDL70 animals (Figure $6 \mathrm{~A}$ ). Lung elastance was further elevated following AdTGF- $\beta 1$ /AdVEGF (Figure 6B). These data were confirmed with histology and mRNA: AdTGF- $\beta 1 /$ AdVEGF animals had severe parenchymal damage, with multiple fibroblastic foci and matrix deposition (Figure 6, C and D). While mRNA of fibrosis-related genes from lung homogenate, such as $\alpha$-SMA (Acta2), procollagen-1 $\alpha 2$ (Col1a2), -3 $\alpha 1$ (Col3a1), and fibronectin (Fn1), was elevated in AdTGF- $\beta 1 /$ AdDL70 animals similarly to that shown in previous studies $(22,23)$, mRNA of these genes was even more enhanced in AdTGF- $\beta 1 /$ AdVEGF animals 
Table 1

ELISA results for AdTGF- $\beta 1 /$ AdVEGF and AdTGF- $\beta 1 /$ AdDL70

Day 7

$\begin{array}{cc}\begin{array}{cc}\text { AdTGF- } \beta 1 / \\ \text { AdVEGF }\end{array} & \text { AdTGF- } \beta 1 / \text { } \\ \text { AdDL70 } \\ 25.38 \pm 5.83 & 16.90 \pm 3.19 \\ 135.8 \pm 32.25 & 0 \pm 0 \\ 10.95 \pm 4.11 & 1.02 \pm 0.26\end{array}$

Day 14

$\begin{array}{cc}\begin{array}{c}\text { AdTGF- } \beta 1 / \\ \text { AdVEGF }\end{array} & \begin{array}{c}\text { AdTGF- } \beta 1 / \\ \text { AdDL70 }\end{array} \\ 1.49 \pm 0.71 & 1.01 \pm 0.83 \\ 5.28 \pm 2.50 & 0 \pm 0 \\ 2.17 \pm 0.94 & 0.18 \pm 0.05\end{array}$

Day 28

$\begin{array}{cc}\text { AdTGF- } \beta 1 / & \text { AdTGF- } \beta 1 / \\ \text { AdVEGF } & \text { AdDL70 } \\ 0.07 \pm 0.02 & 0.20 \pm 0.15 \\ 0 \pm 0 & 0 \pm 0 \\ 0.36 \pm 0.06 & 0.42 \pm 0.08\end{array}$

Each value represents mean \pm SEM. $n=5$ to 6 animals per group.

(Table 2). Plasminogen activator inhibitor-1 (Pai1) was augmented in AdTGF- $\beta 1 /$ AdVEGF compared with AdTGF- $\beta 1 /$ AdDL70, indicating increased TGF- $\beta$ activity (Table 2 ). The combined data from histology, physiology, and gene expression indicate that treatment with AdTGF- $\beta 1 /$ AdVEGF induces more extensive PF than treatment with AdTGF- $\beta 1 /$ AdDL70.
AdTGF- $\beta 1 /$ AdVEGF animals had transient protein leakage by day 7 , as demonstrated by an increased albumin BALF/plasma ratio (Table 1). Albumin extravasation returned toward baseline by day 14 (Table 1). There was a temporary induction of eNos (days 7 and 14) compared with AdTGF- $\beta 1 /$ AdDL70 (Table 2). At the same time, eNos mRNA was reduced in AdTGF- $\beta 1 /$ AdDL70 versus
A

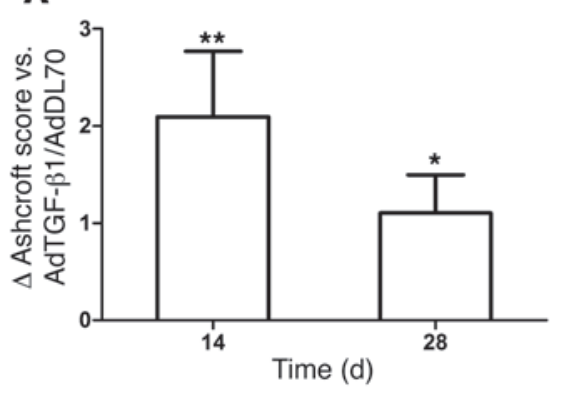

B
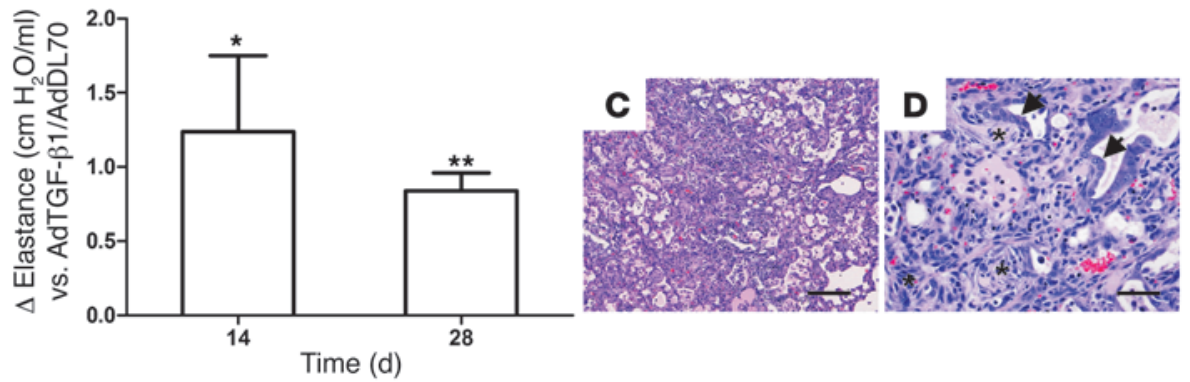

$\mathbf{H}$
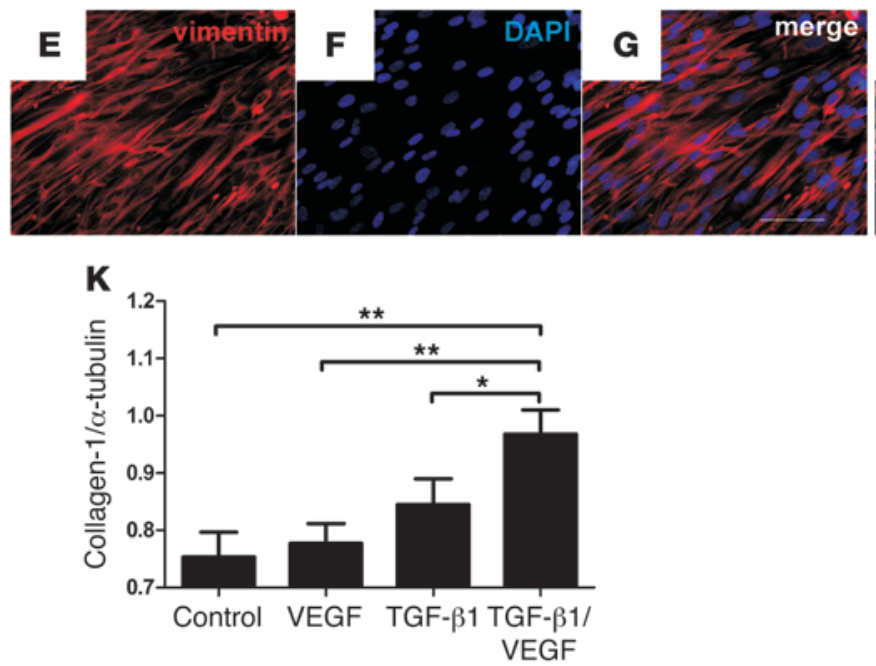

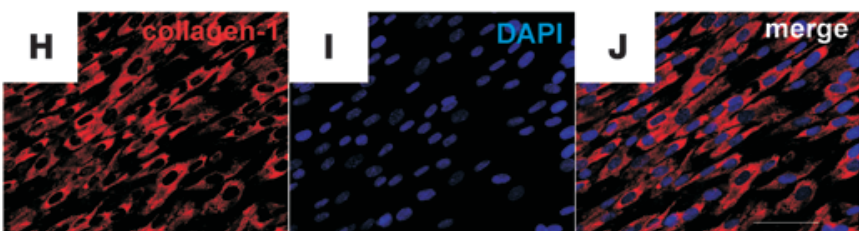

$\mathbf{L}$

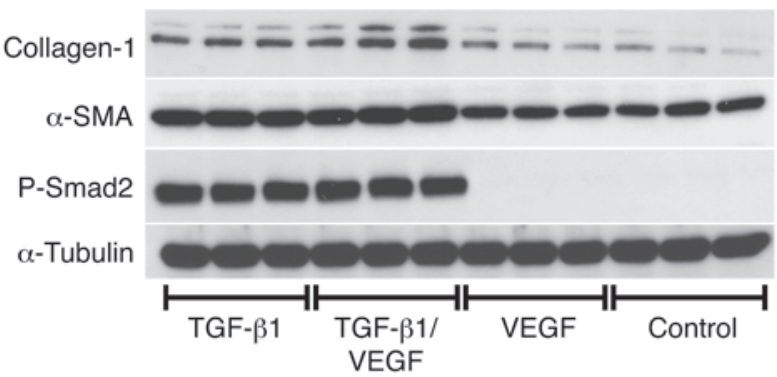

Figure 6

Increased PF following AdTGF- $\beta 1$ /AdVEGF compared with AdTGF- $\beta 1 /$ AdDL70 administration. (A and B) AdTGF- $\beta 1 /$ AdVEGF animals have an additionally increased PF score (A) and elevated elastance (B) compared with AdTGF- $\beta 1 / A d D L 70$. Values are expressed as differences from AdTGF- $\beta 1 /$ AdDL70. (C and D) Multiple fibroblastic foci (asterisks), hyperplastic epithelial cells (arrows), and extensive deposition of matrix in lungs of AdTGF- $\beta 1$ /AdVEGF animals at day 14. H\&E staining. Original magnification, $\times 100$ (C); $\times 400$ (D). Scale bars: $200 \mu \mathrm{m}$ (C); $50 \mu \mathrm{m}$ (D). $(\mathbf{E}-\mathbf{J})$ Characterization of primary human lung fibroblasts as vimentin-positive $(\mathbf{E}-\mathbf{G})$ and collagen-1-positive $(\mathbf{H}-\mathbf{J})$. Original magnification, $\times 400$. Scale bars: $50 \mu \mathrm{m}$. (K and L) Lung fibroblasts showed enhanced collagen-1 expression after 24-hour stimulation with $5 \mathrm{ng} / \mathrm{ml}$ human TGF- $\beta 1$ and an additional increase following $30 \mathrm{ng} / \mathrm{ml}$ human VEGF and $5 \mathrm{ng} / \mathrm{ml}$ human TGF- $\beta 1$. Collagen-1 protein was not induced after stimulation with VEGF alone. (K) densitometry of 2 independent experiments $(n=3$ each) of 2 fibroblast lines. Values are given as ratio of collagen-1 to $\alpha$-tubulin density. ${ }^{\star} P<0.05 ;{ }^{\star} P<0.01,1$-way ANOVA. (L) Representative Western blot showing collagen-1, $\alpha$-SMA, and P-Smad2 induction after TGF- $\beta 1$ or TGF- $\beta 1$ and VEGF administration. $\alpha$-tubulin was used as a loading control. Each condition is represented by 3 adjacent bands. 


\section{Table 2}

Quantitative real-time PCR results for AdTGF- $\beta 1 /$ AdVEGF vs. AdTGF- $\beta 1 /$ AdDL70

$\begin{array}{llcc}\text { Gene } & \text { Day } \mathbf{7} & \text { Day } \mathbf{1 4} & \text { Day 28 } \\ \text { Acta2 } & 1.40 \pm 0.16 & 1.75 \pm 0.27^{\mathrm{A}} & 0.94 \pm 0.08 \\ \text { Col1a2 } & 0.87 \pm 0.058 & 1.99 \pm 0.23^{\mathrm{B}} & 1.39 \pm 0.32 \\ \text { Col3a1 } & 0.87 \pm 0.063 & 3.32 \pm 0.93^{\mathrm{A}} & 2.03 \pm 0.54 \\ \text { Fn1 } & 0.84 \pm 0.14 & 3.27 \pm 0.83^{\mathrm{A}} & 1.58 \pm 0.32 \\ \text { Pai1 } & 2.44 \pm 0.71^{\mathrm{A}} & 3.00 \pm 0.50^{\mathrm{B}} & 0.64 \pm 0.14 \\ \text { eNos } & 1.52 \pm 0.15^{\mathrm{A}} & 3.17 \pm 1.10^{\mathrm{A}} & 0.97 \pm 0.26\end{array}$

Each value represents mean \pm SEM of $n$-fold vs. AdTGF- $\beta 1 /$ AdDL70. $n=5$ to 6 animals per group. ${ }^{A} P<0.05$; ${ }^{B} P<0.0001$ AdTGF- $\beta 1 /$ AdVEGF vs. AdTGF- $\beta 1 /$ AdDL70, Student's $t$ test. Acta2, $\alpha$-SMA; Col1a2, procollagen-1 $\alpha 2$; Col3a2, procollagen-3 $\alpha 1$; Fn1, fibronectin.

AdDL70 (not shown), similar to what is shown in Figure 4C. By day 28, eNos mRNA was expressed at similar levels for AdTGF- $\beta 1 /$ AdVEGF and AdTGF- $\beta 1 /$ AdDL70.

Primary human lung fibroblasts were more than $95 \%$ vimentin and collagen-1 positive (Figure 6, E-J) and negative for CD31, $\mathrm{CD} 45$, and E-cadherin. Collagen-1 was induced after 24-hour stimulation with $5 \mathrm{ng} / \mathrm{ml} \mathrm{TGF-} \beta 1$ and augmented by addition of $30 \mathrm{ng} / \mathrm{ml}$ VEGF (Figure 6, K and L). VEGF alone did not affect collagen-1 (Figure $6, \mathrm{~K}$ and $\mathrm{L}$ ). Induction of $\alpha$-SMA in response to 24 -hour TGF- $\beta 1$ or combined TGF- $\beta 1 /$ VEGF exposure and phosphorylation of Smad2 was seen (Figure 6L).

Increased microvascular density via decreased EC apoptosis after $A d T G F-\beta 1 / A d V E G F$. Concomitant overexpression of TGF- $\beta 1$ and VEGF induced sustained increase in $\mathrm{CD} 31^{+}$and $\mathrm{CD} 34^{+}$area in severely fibrotic tissue (Ashcroft 6-8) from day 7 compared with AdTGF- $\beta 1 /$ AdDL70 (Figure 7, A, B, D, and E). No difference was seen between AdTGF- $\beta 1 /$ AdVEGF and AdTGF- $\beta 1 /$ AdDL70 in regions of moderate (Ashcroft 2-5) or no (Ashcroft 0-1) PF (not shown). Both AdTGF- $\beta 1 /$ AdVEGF and AdTGF- $\beta 1 /$ AdDL70 animals showed increased $\mathrm{CD} 34^{+}$areas in nonfibrotic zones (not shown). Double immunofluorescence revealed elevated CD34 positivity around but not within $\alpha$-SMA ${ }^{+}$fibroblastic foci (Figure 7C). Microvascular apoptosis was reduced in highly fibrotic areas of AdTGF- $\beta 1 /$ AdVEGF animals by day 7 (Figure 7, F-I). No differences were seen in Ashcroft $0-1$ and 2-5 areas at day 7. In accordance with VEGF overexpression, we found augmented numbers of P-VEGFR2 ${ }^{+} \mathrm{CD}_{34} 4^{+}$cells in Ashcroft 6-8 areas by day 7 (Figure 7J).

Vascular remodeling and $P H$ and $P A$ EC apoptosis in AdTGF- $\beta 1 / A d V E G F$ animals. Coadministration of AdTGF- $\beta 1$ and AdVEGF resulted in reduced mPAP by day 14 and day 28 (Figure $7 \mathrm{~K}$ ). AdTGF- $\beta 1 /$ AdVEGF attenuated MWT compared with AdTGF- $\beta 1 /$ AdDL70 (Figure 7, L and M). The percentage of apoptotic (caspase- $3^{+}$and cleaved caspase- $3^{+}$) ECs was decreased in small PA, while medium PA had a trend toward reduced EC apoptosis (Figure 7, N and O).

\section{Discussion}

The detailed pathogenesis of secondary PH in PF is unclear. In this study, we demonstrate that progressive PF, induced by adenovirusmediated overexpression of active TGF- $\beta 1$, leads to pulmonary vascular remodeling and $\mathrm{PH}$. Vascular density decreased with rising severity of PF but increased in unaffected regions. There was a spatiotemporal relationship between increasing PF, high TGF- $\beta$ activity, loss of microvascularization, and remodeling of PA. We found augmented apoptosis of both microvascular and PA ECs in areas of severe interstitial damage. VEGF expression was reduced in fibrotic lungs and correlated inversely with mPAP. We assumed a mechanistic link between impaired angiogenesis and $\mathrm{PH}$ and used concomitant overexpression of TGF- $\beta 1$ and VEGF genes to investigate this possible connection. We showed that VEGF enhancement reduced apoptosis of microvascular and PA ECs, partly prevented vascular rarefaction, attenuated $\mathrm{PA}$ remodeling, and reduced $\mathrm{PH}$. However, augmented VEGF expression also exaggerated PF, indicating that VEGF facilitates the fibrogenic process.

The prevalence of $\mathrm{PH}$ in human IPF is as high as $40 \%$ and is associated with poor prognosis $(6,8)$, emphasizing the need for a better understanding of the underlying mechanisms. Experimental PF was induced by transient overexpression of a mutated TGF- $\beta 1$ gene, resulting in release of high levels of constitutively active TGF- $\beta 1$ (21). We demonstrated that areas with high fibrogenic activity were also regions of increased TGF- $\beta$ activity, as indicated by the presence of P-Smad2. One single intratracheal administration results in expression of the exogenous gene for approximately 10 days with severe and progressive PF (21). The patchy distribution of PF, fibroblastic foci, accumulation of myofibroblasts, and increased deposition of ECM makes this a suitable model for studying the pathogenesis of IPF $(21,23)$. In addition, PF seen in this model is not reversible, in which it differs somewhat from the bleomycin model (24), and allows one to investigate complex and long-term biological changes, such as secondary $\mathrm{PH}$.

Vessel abnormalities in IPF involve all sections of the vascular bed (6). In our study, relative MWT of PA, a common parameter of vascular remodeling in experimental $\mathrm{PH}$, increased early, and $\mathrm{PH}$ was functionally established by day 14. MWT increased gradually, with rising degrees of PF, similar to human IPF (25). The most fibrotic areas with the highest MWT also had high levels of active TGF- $\beta$, suggesting a close relationship among fibrogenesis, decreased vascularization, PA remodeling, and TGF- $\beta$ signaling. This pattern of MWT may partially be due to direct effects of TGF- $\beta$ on PA VSMC, as TGF- $\beta$ has been shown to affect muscularization of PA $(26,27)$. The lack of a clear pattern of P-Smad2 immunoreactivity in the PA medium can also argue for the involvement of secondary mediators, such as endothelin-1, angiotensin II, PDGF, or the BMP antagonist gremlin, which are either induced by TGF- $\beta$ itself or by other factors in the fibrotic tissue $(4,28-31)$.

Another phenomenon in IPF lungs is vessel loss in severely fibrotic regions compared with augmented (and CD34+) vascularization in nonfibrotic areas $(10,11,32)$. In our model, we saw a dramatic reduction of vessels and increased EC apoptosis with an increasing degree of PF (21). One possible explanation for this is direct induction of EC apoptosis by TGF- $\beta$ (33). Apoptosis of ECs may also contribute to PA remodeling via release of secondary mediators leading to VSMC proliferation (34). Therefore, we further investigated the role of EC apoptosis during early fibrogenesis and its influence on PH. We noted an enhancement of capillaries in normal lung areas, detected by positive staining for CD34 but not CD31. In cancer research, CD34 indicates the presence of immature endothelium (35), suggesting that the vessels seen in our study are newly developed through angiogenesis. However, it has to be considered that CD34 is also expressed on hematopoietic progenitor cells including fibrocytes, a recently identified cell type that is possibly involved in the pathogenesis of PF (36), and that positive staining may not exclusively indicate neoangiogenesis. Nevertheless, extent and distribution of vascular rarefac- 

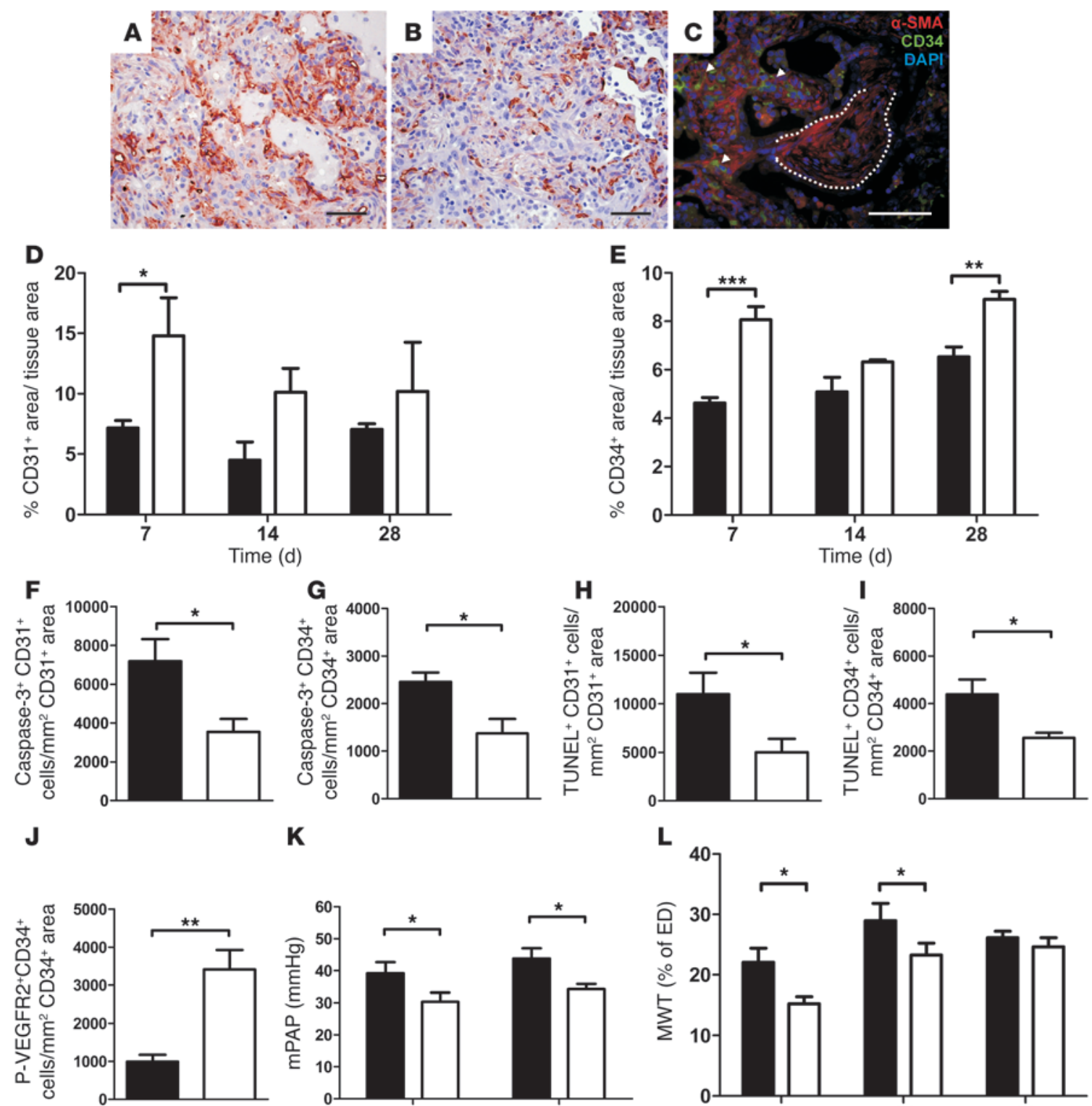

\section{K}
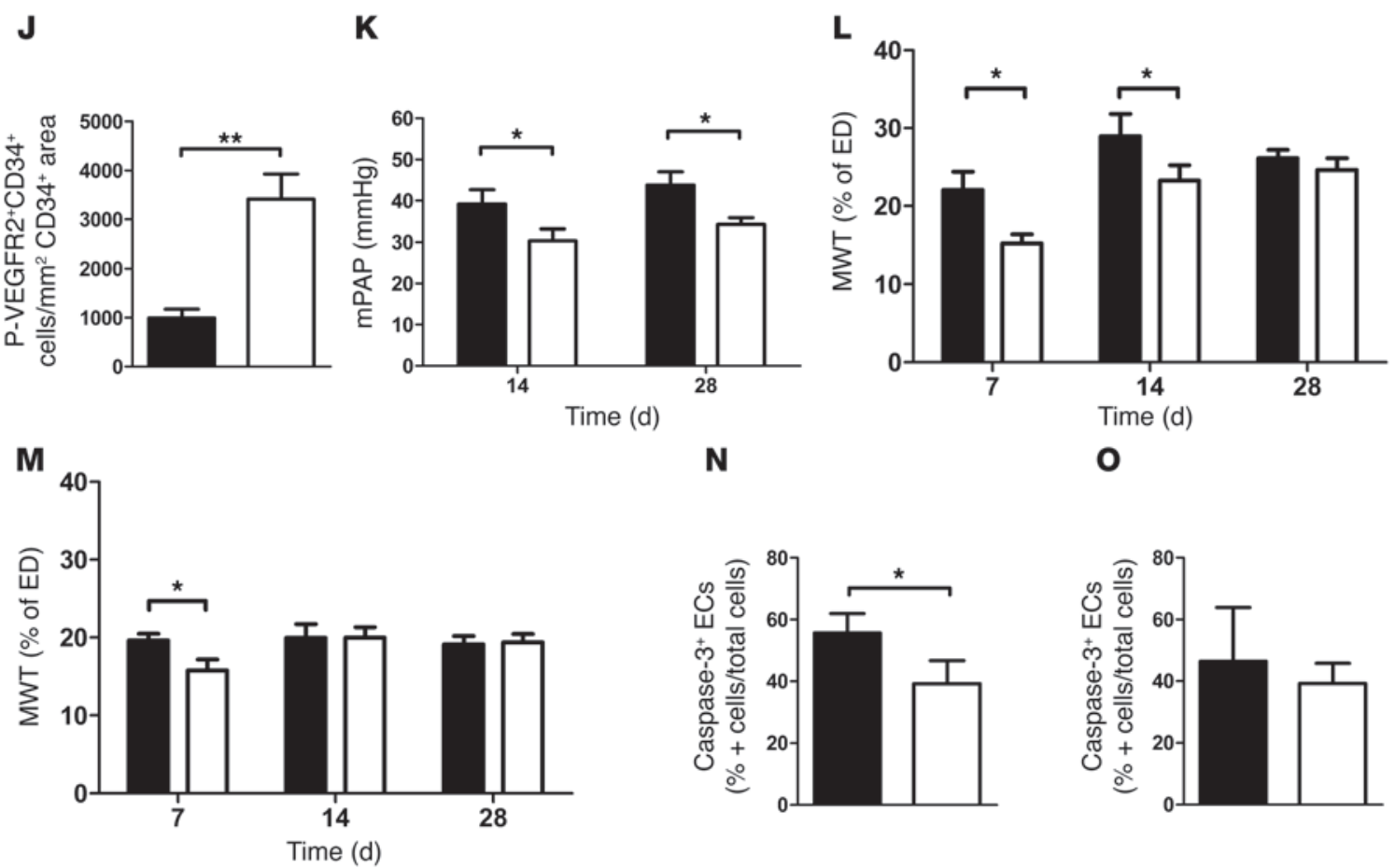

$\mathbf{N}$

o
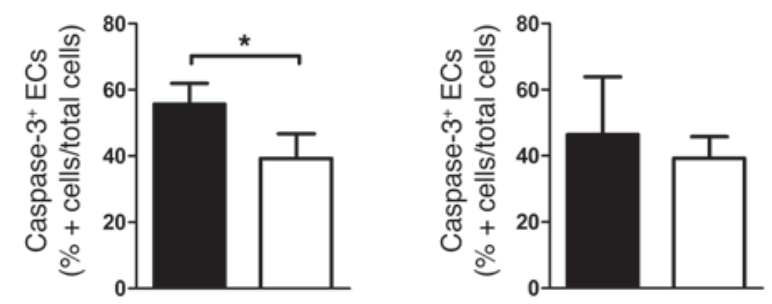


\section{Figure 7}

Increased vascular density, decreased EC apoptosis, decelerated vascular remodeling, and improved PH in AdTGF- $\beta 1 /$ AdVEGF animals. (A and C) Representative images of CD34 IHC for AdTGF- $\beta 1 /$ AdVEGF (A) and AdTGF- $\beta 1 /$ AdDL70 (B) at day 7. (C) Representative CD34 and $\alpha$-SMA double immunofluorescence of AdTGF- $\beta 1 /$ AdVEGF animal at day 14: no vascularization within $\alpha-S M A^{+}$fibroblastic foci (dotted lines) but augmented capillary density in adjacent areas (arrows). Original magnification, $\times 400$. Scale bars: $50 \mu \mathrm{m}$. (D-J) Increased CD31+ (D) and $\mathrm{CD}_{4}{ }^{+}(\mathrm{E})$ area in highly fibrotic regions (Ashcroft $6-8$ ) of AdTGF- $\beta 1 /$ AdVEGF animals. AdTGF- $\beta 1 /$ AdVEGF animals have reduced EC apoptosis in highly fibrotic regions (Ashcroft 6-8) at day 7 as shown by quantitative double immunofluorescence for caspase- $3^{+} \mathrm{CD} 31^{+}(\mathbf{F})$, caspase $-3^{+} \mathrm{CD} 34^{+}(\mathbf{G})$, TUNEL ${ }^{+} \mathrm{CD} 31^{+}(\mathbf{H})$, and TUNEL ${ }^{+} \mathrm{CD} 34^{+}(\mathbf{I})$. Augmented VEGFR2 phosphorylation of ECs (P-VEGFR2 ${ }^{+} \mathrm{CD} 34^{+}$cells) is found for Ashcroft 6-8 areas (day 7) of AdTGF- $11 /$ AdVEGF animals in J. (K-O) mPAP is decreased in AdTGF- $\beta 1 /$ AdVEGF (K). The development of vascular remodeling is decelerated in AdTGF- $\beta 1 /$ AdVEGF. MWT for small (ED < $50 \mu \mathrm{m}, \mathrm{L})$ and medium $(50 \mu \mathrm{m} \leq \mathrm{ED}<100 \mu \mathrm{m}, \mathrm{M})$ PA. Apoptosis of PA EC in small (N) vessels is lower in severely fibrotic areas (Ashcroft 6-8) of AdTGF- $\beta 1 /$ AdVEGF at day 7. For medium PA, a trend is found ( $\mathbf{O})$. Data confirmed by cleaved caspase-3 (not shown). Black bars show AdTGF- $\beta 1 /$ AdDL70; white bars show AdTGF- $\beta 1 /$ AdVEGF. Each bar represents mean \pm SEM of 5-6 animals per group (D, E, and $\mathbf{K}-\mathbf{M})$ or 3-4 animals per group $(\mathbf{F}-\mathbf{J}, \mathbf{N}$, and $\mathbf{O})$. ${ }^{*} P<0.05$; ${ }^{* *} P<0.01 ;{ }^{* *} P<0.0001,1$-way ANOVA or Student's $t$ test.

tion in fibrotic lungs combined with increased capillary density in adjacent regions reflect the changes seen in human IPF $(11,32)$. Expression of vascular density as ratio of capillary area to total tissue area has been reported before for IPF but represents a potential limitation of some of our results $(10,32)$. Therefore, we have also provided data indicating peripheral rarefaction of the vascular tree in fibrotic areas with a relevant overall reduction of vessel density in fibrotic lungs, independent of tissue density. In contrast to our findings, deprivation of the vascular bed is not seen in the bleomycin model (37). This may be due to severe inflammation in bleomycin-induced lung injury, with a profound impact on angiogenesis and vascular function independent of PF (24).

VEGF is an important survival signal for ECs and promotes angiogenesis (38). Vegf and Vegfr-2 mRNA were reduced in the lungs of AdTGF- $\beta 1$-treated rats, correlating inversely with mPAP. We noted a pronounced decrease in VEGF, particularly in fibroblastic foci and fibrotic interstitium, while hyperplastic and normal epithelial cells were positive for VEGF, similar to human IPF $(10,11,39,40)$. Costainings indicated that areas with increased TGF- $\beta$ activity also lack VEGF and vascularization. We further found that PEDF, a potent antiangiogenic factor, was highly expressed in fibrotic lungs and was most obvious in fibroblastic foci, fibrotic interstitium, and epithelial cells, again similar to IPF (11). PEDF was colocalized with collagen-1, possibly explaining its sustained positivity in fibrotic scars due to a collagen-1-binding site (41). This might indicate a shift in the PEDF-VEGF relationship toward a (regional) antiangiogenic environment, with the consequence of vessel loss and secondary PH $(11,39)$. PEDF negatively regulates VEGF-mediated angiogenesis on different levels and induces apoptosis of EC $(19,20,42)$, and we propose PEDF-mediated inhibition of VEGF-induced angiogenesis as one potential mechanism involved in vascular rarefaction in IPF. Therefore it is not surprising that we noted reduced VEGFR2 phosphorylation in $\mathrm{CD}_{3} 4^{+}$cells with rising degrees of $\mathrm{PF}$, which might explain EC apoptosis $(43,44)$. The structural composition of different compartments can lead to different effects of TGF- $\beta 1$ on angiogenesis and EC survival, as contradictory in vivo and in vitro findings suggest (45-47).

In order to prove a regulatory role of VEGF on angiogenesis and a link among vessel loss, EC apoptosis, and $\mathrm{PH}$, we overexpressed both TGF- $\beta 1$ and VEGF. Interestingly, combined exposure to both caused more extensive PF than exposure to TGF- $\beta 1$ alone, as demonstrated by histomorphometry, elastance, and gene expression of ECM and $\alpha$-SMA. Pail mRNA was increased following concomitant overexpression, indicating augmented TGF- $\beta$ activity. The order of the changes suggests that they represent direct or indirect effects of the transduced genes. Our in vitro data also argue for an additive effect of TGF- $\beta 1$ and VEGF on collagen- 1 expression in lung fibroblasts. This supports a contribution of VEGF to the fibrotic process via induction of angiogenesis and direct effects on mesenchymal cells $(13,14,48)$. Further, a transient protein leakage following AdTGF- $\beta 1 /$ AdVEGF could add to the initial injury and thereby promote fibrogenesis.

Combined delivery of AdVEGF and AdTGF- $\beta 1$ attenuated vascular remodeling and reduced mPAP compared with delivery of AdTGF- $\beta 1$ plus AdDL70. Gene transfer of VEGF has improved monocrotaline- and hypoxia-induced $\mathrm{PH}$, likely through microvascular regeneration and correction of EC dysfunction (49-51). In our study, animals simultaneously overexpressing TGF- $\beta 1$ and VEGF showed enhanced microvascularization in severely fibrotic areas compared with those overexpressing TGF- $\beta 1$ plus control. Vascular density was increased in the fibrotic interstitium surrounding fibroblastic foci, while the foci themselves remained vessel free. This suggests that the proangiogenic VEGF reduced EC apoptosis through signaling via VEGFR2 and partially prevented the loss of small vessels, thereby counteracting angiogenesis inhibition in TGF- $\beta$-induced PF. However, VEGF did not affect the increased vascularization seen in nonfibrotic areas of the fibrotic lung. It is possible that other mechanisms contribute to the changes in our model, such as vasoconstriction (16). VEGF may also improve EC function and prevent apoptosis through transient restoration of eNOS activity. Similar effects have been shown in a hypoxia model of $\mathrm{PH}$ or the bleomycin model $(51,52)$. While many of the effects of additional VEGF, such as protein leakage, edema, or eNOS induction, were transient and depended on the transgenic protein, only the increase in microvascular density following reduced EC apoptosis was sustained. In contrast, muscularization of PA developed in a delayed manner compared with AdTGF- $\beta 1 /$ AdDL70. We argue that PA remodeling is mainly induced through 2 possible mechanisms. One is release of secondary mediators from apoptotic ECs that induce VSMC proliferation (e.g., TGF- $\beta$, angiotensin II, or endothelin-1) early on. The second consists of direct effects of TGF- $\beta$ and production of similar factors in the fibrotic tissue surrounding PA at a later time. Decelerated media thickening could result from decreased mediator release because of reduced EC apoptosis in the early phase. This strongly suggests EC apoptosis as an important mechanism by which vascular remodeling develops during fibrogenesis (Figure 8). The overall reduction of EC apoptosis following concomitant overexpression of TGF- $\beta 1$ and VEGF despite increased TGF- $\beta$ activity in the tissue highlights reduced VEGF activity as the more important mechanism and suggests a lesser relevance of TGF- $\beta$-dependent EC apoptosis.

There is a significant controversy in the literature regarding angiogenesis and vascularity in IPF. Several factors have been implicated in fibrogenesis. ELR ${ }^{+} \mathrm{CXC}$ chemokines (CXC chemo- 


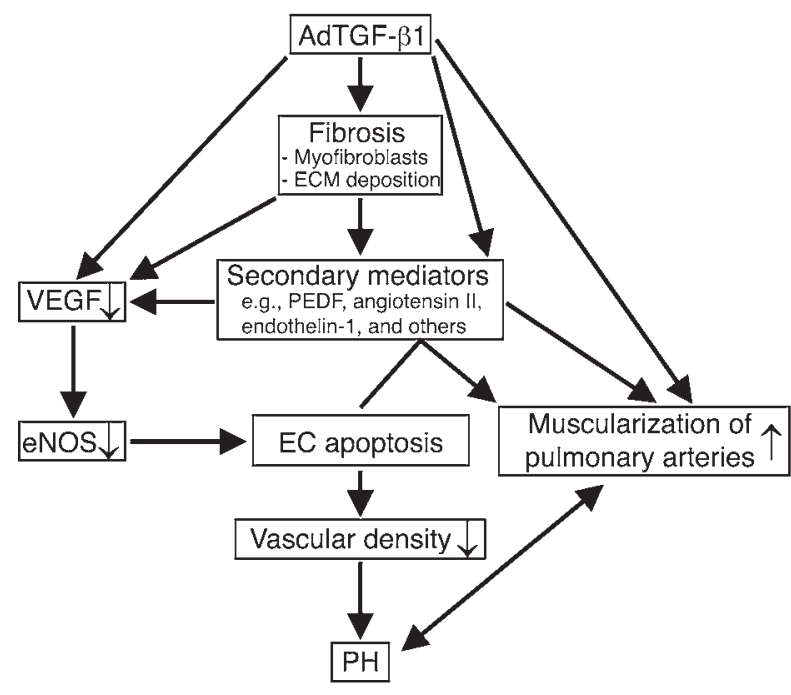

kines containing the amino acid sequence Glu-Leu-Arg [ELR] immediately before the first cysteine residue) (e.g., CXCL5 or CXCL8) have proangiogenic effects and may promote PF, while ELR- CXC chemokines (e.g., CXCL10) are antiangiogenic and may inhibit fibrogenesis (53). Our study clearly confirms that a proangiogenic factor (VEGF) can exaggerate PF. We believe that there is an overall antiangiogenic environment in fibrotic tissue and explain this by local VEGF inhibition. The negative effects of PEDF on regional angiogenesis through VEGF inhibition might be overriding the effects of proangiogenic chemokines, thereby resulting in net vascular loss. The clinical relevance of our findings becomes obvious, as VEGF inhibition has been investigated as a potential therapy for IPF based on experiments showing a beneficial antifibrotic effect of anti-VEGF compounds $(13,14)$. These studies used the bleomycin model of PF, which involves inflammation and induces a proangiogenic environment in the lungs (14). The experiments did not include investigation of secondary $\mathrm{PH}$, which - considering our data - might be exaggerated following VEGF inhibition. This therapeutic approach might limit the progression of PF but may also negatively affect pulmonary hemodynamics. In addition, it is unclear to what extent VEGF inhibition will be clinically successful in lungs that already have decreased VEGF activity. Regardless of this, the currently ongoing clinical trials using compounds with anti-VEGF activity should consider the potential for development of PH in these studies.

In summary, our data strongly support observational studies in human IPF that suggested that a decrease in vascularity is involved in vascular remodeling and the development of secondary $\mathrm{PH}$ in PF. We propose that the upregulation of PEDF and consequential inhibition of VEGF in both idiopathic human and experimental PF represent compensatory mechanisms to limit fibrogenesis. At the same time, the relative lack of VEGF, the increase in EC apoptosis, and the subsequent rarefaction of vascular structures together with mediator-induced PA remodeling result in $\mathrm{PH}$, an important clinical indicator of poor prognosis in IPF. Both angiogenesis and its inhibition might have significant negative effects in fibrotic lungs. Further animal studies and careful follow-up of IPF patients in clinical trials should be conducted to assess whether antiangiogenic therapy may result in enhanced $\mathrm{PH}$ in the context of IPF.

\section{Figure 8}

Hypothetical synopsis of the development of $\mathrm{PH}$ in experimental PF. Transient overexpression of active TGF- $\beta 1$ in rodent lung induces PF with myofibroblast accumulation and deposition of ECM. VEGF and VEGF signaling are decreased early on during fibrogenesis by direct actions of TGF- $\beta 1$ as a result of tissue damage (e.g., epithelial apoptosis) or by secondary mediators such as PEDF. The consequence of decreased VEGF is reduced eNOS expression, with the result being apoptosis of ECs and vascular rarefaction. In addition, other secondary mediators (e.g., angiotensin II, endothelin-1) are released as an effect of EC apoptosis (earlier) and fibrogenesis (later) and induce remodeling of PA walls together with TGF- $\beta$. All these processes, reduced vascular density, and mediator-related PA remodeling finally culminate in $\mathrm{PH}$, which will augment the remodeling process of $\mathrm{PA}$ in the form of a vicious circle. Note the central importance of EC apoptosis for both reduced vascular density and PA muscularization in this concept.

\section{Methods}

Recombinant adenovirus. The construction of adenoviral vectors is described elsewhere (54). This study involved AdTGF- $\beta 1$ (21) and AdVEGF (constructed by F. Pitossi, Campomar Foundation, Buenos Aires, Argentina, and provided by D. Anthony, University of Southampton, Southampton, United Kingdom), both under human CMV promoter. AdDL70 (empty virus) served as control.

Animal experiments. Procedures were approved by the McMaster University Institutional Animal Ethics Board. Female Sprague-Dawley rats (Charles River), $225-250 \mathrm{~g}$, received $1 \times 10^{8}$ PFU AdTGF- $\beta 1$, AdDL70, AdTGF- $\beta 1 /$ AdDL70, or AdTGF- $\beta 1 /$ AdVEGF $\left(1 \times 10^{8}\right.$ PFU each $)$ intratracheally under isoflurane anesthesia. Right-heart catheterization was done with ketamine/ xylazine anesthesia: A fluid-filled radial artery catheter connected to a pressure transducer (Hewlett-Packard) was introduced into the jugular vein and advanced to the PA with continuous pressure tracing. Elastance was assessed by pressure-volume loops with a respirator (flexiVent; SCIREQ). Animals were sacrificed by abdominal bleeding after blood withdrawal. Lung and heart were removed, and $5 \mathrm{ml}$ PBS was used to obtain BALF.

Histological evaluation. Left lungs were inflated with $10 \%$ formalin at a pressure of $20 \mathrm{~cm} \mathrm{H}_{2} \mathrm{O}$, fixed for 24 hours, and paraffin embedded; $5-\mu \mathrm{m}$ sections were stained with $\mathrm{H} \& \mathrm{E}$, picro-sirius red (PSR), and elastica van Giesson (EvG). Images were acquired with Axio Scope microscope and AxioVision 3.1 software; for PSR and immunofluorescence they were acquired with an Axiovert microscope (all Carl Zeiss). Collagen was quantified according to Ashcroft (55). 20 pictures (PSR, dark field, polarization filter) were randomly taken of 4 transversal sections at $\times 25$ magnification. Pictures were scored from 0 (no PF) to 8 (maximal PF) by 2 blinded investigators. Histomorphometry was used to quantify vascular remodeling: ED and MWT were measured for 30-40 PA $(\mathrm{EvG})$ in 2 orthogonal directions using AxioVision 3.1 software. ED was defined as distance between external elastic laminae, while MWT was determined as distance between external and internal elastic laminae. Vessels were categorized as follows: $25<\mathrm{ED}<50 \mu \mathrm{m}$ and $50 \leq \mathrm{ED}<100 \mu \mathrm{m}$. MWT was calculated using the following formula: MWT $(\%)=(2 \times \mathrm{MT} / \mathrm{ED}) \times 100 \%$.

Ashcroft scores were assigned to each vessel image to further categorize the tissue surrounding the PA according to the degree of PF. For VAR, images $(\times 100)$ completely covering 1 whole transversal section of the left lower lobe at hilar level were used. Total vessels (excluding bronchial arteries) were counted and categorized according to ED as described above. Each image was assigned a fibrotic score. The TCA (tissue area plus nontissue area, such as in bronchial or vessel lumen and alveolar space) was determined by ImageJ software (56). VAR was given as number of vessels $/ \mathrm{mm}^{2} \mathrm{TCA}$.

Preparation of lung homogenate and RNA isolation. Right lung was homogenized in TRIzOL (Invitrogen), and RNA was extracted (57). RNA was DNase treated and reverse transcribed. Quantitative real-time PCR was conducted 
Table 3

List of primary and secondary antibodies

\begin{tabular}{|c|c|c|c|c|}
\hline Antigen & Antibody & Dilution & Secondary antibody & Dilution \\
\hline \multirow[t]{2}{*}{$\alpha-S M A$} & M0851 (DAK0) & $1: 100^{A}$ & T2402A,B (Sigma-Aldrich) & $1: 400^{A, B}$ \\
\hline & & $1: 2,000^{C}$ & No. 7076C (Cell Signaling Technology) & $1: 2,000^{C}$ \\
\hline$\alpha$-Tubulin & No. 2144 (Cell Signaling Technology) & $1: 1,000^{c}$ & No. 7074C (Cell Signaling Technology) & $1: 2,000 c$ \\
\hline Caspase-3 & No. 9662 (Cell Signaling Technology) & $1: 100^{A, D}$ & $\begin{array}{c}\text { A21207A,E(Invitrogen) } \\
\text { AP132BD (Chemicon; Millipore) }\end{array}$ & $\begin{array}{l}1: 500^{\mathrm{A}, \mathrm{E}} \\
1: 1500^{\mathrm{D}}\end{array}$ \\
\hline $\begin{array}{l}\text { Caspase- } 3 \text {, } \\
\text { cleaved }\end{array}$ & No. 9664 (Cell Signaling Technology) & $1: 100^{D}$ & AP132BD (Chemicon) & $1: 1500^{\circ}$ \\
\hline CD31 & Sc-1506 (Santa Cruz Biotechnology Inc.) & $\begin{array}{l}1: 1,000^{D} \\
1: 200^{A, F}\end{array}$ & $\begin{array}{l}\text { AP106BD (Chemicon; Millipore) } \\
\text { F7367A,F,G (Sigma-Aldrich) }\end{array}$ & $\begin{array}{l}1: 2,000^{D} \\
1: 400^{A, F, G}\end{array}$ \\
\hline CD34 & AF4117 (R\&D Systems) & $\begin{array}{l}1: 1500^{D} \\
1: 100^{A}\end{array}$ & $\begin{array}{l}\text { AP106BD (Chemicon; Millipore) } \\
\text { F7367A,G (Sigma-Aldrich) and 805-095-180A,G } \\
\text { (Jackson ImmunoResearch Laboratories Inc.) }\end{array}$ & $\begin{array}{c}1: 1500^{\mathrm{D}} \\
1: 400(\mathrm{~F} 7367)^{\mathrm{A}, \mathrm{G}} \text { and } \\
1: 100(805-095-180)^{\mathrm{A}, \mathrm{G}}\end{array}$ \\
\hline CD45 & 557513 (BD Biosciences — Pharmingen) & $1: 10^{\mathrm{F}}$ & & \\
\hline Collagen-I & $\begin{array}{c}\text { Ab6308 (Abcam) } \\
600-401-103 \text { (Rockland) }\end{array}$ & $\begin{array}{c}1: 50^{\mathrm{A}} \\
1: 200^{\mathrm{F}} \\
1: 5,000^{\mathrm{C}}\end{array}$ & $\begin{array}{c}\text { T2402A,B (Sigma-Aldrich) } \\
\text { A21207 F, (Invitrogen) } \\
\text { No. 7074C (Cell Signaling Technology) }\end{array}$ & $\begin{array}{l}1: 400^{\mathrm{A}, \mathrm{B}} \\
1: 500^{\mathrm{F}, \mathrm{E}} \\
1: 2,000^{\mathrm{C}}\end{array}$ \\
\hline E-cadherin & Sc-7870 (Santa Cruz Biotechnology Inc.) & $1: 250^{\mathrm{F}}$ & A21207 (Invitrogen)F,E & $1: 500^{\mathrm{F}, \mathrm{E}}$ \\
\hline PEDF & Sc-25594 (Santa Cruz Biotechnology Inc.) & $1: 100^{A, D}$ & $\begin{array}{l}\text { AP132BD (Chemicon; Millipore) } \\
\text { F1262A,G (Sigma-Aldrich) and } \\
\text { A21207 }{ }^{\mathrm{A}, \mathrm{E}} \text { (Invitrogen) }\end{array}$ & $\begin{array}{c}1: 1500^{D} \\
1: 75(\mathrm{~F} 1262)^{A, G} \\
1: 500(\mathrm{~A} 21207)^{A, E}\end{array}$ \\
\hline P-Smad2 & No. 3101 (Cell Signaling Technology) & $\begin{array}{l}1: 1,000^{\mathrm{D}} \\
1: 1,000^{\mathrm{A}} \\
1: 2,000^{\mathrm{C}}\end{array}$ & $\begin{array}{c}\text { AP132BD (Chemicon; Millipore) } \\
\text { A21207A,E (Invitrogen) } \\
\text { No. 7074C (Cell Signaling Technology) }\end{array}$ & $\begin{array}{c}1: 1500^{\mathrm{D}} \\
1: 1,000^{\mathrm{A}, \mathrm{E}} \\
1: 2,000^{\mathrm{C}}\end{array}$ \\
\hline P-VEGFR2 & Sc-101819 (Santa Cruz Biotechnology Inc.) & $1: 10^{\mathrm{A}}$ & A21207A,E (Invitrogen) & $1: 250^{A, E}$ \\
\hline VEGF & AF564 (R\&D Systems) & $1: 10^{A, D}$ & $\begin{array}{l}\text { AP106BD (Chemicon; Millipore) } \\
\text { F7367A,G (Sigma-Aldrich) and 805-095-180 A,G } \\
\text { (Jackson ImmunoResearch Laboratories Inc.) }\end{array}$ & $\begin{array}{c}1: 1500^{\mathrm{D}} \\
1: 200(\mathrm{~F} 7367)^{\mathrm{A}, \mathrm{G}} \text { and } \\
1: 100(805-095-180)^{\mathrm{A}, \mathrm{G}}\end{array}$ \\
\hline Vimentin & Sc-32322 (Santa Cruz Biotechnology Inc.) & $1: 100^{F}$ & T2402,B (Sigma-Aldrich) & $1: 400^{F, B}$ \\
\hline
\end{tabular}

AImmunofluorescence. BTRITC conjugated. CWestern blotting. DIHC. FImmunocytofluorescence. EAlexa Fluor 594 conjugated. GFITC conjugated.

with ABI Prism 7500 (Applied Biosystems). RT-PCR probe and primer sets were from Applied Biosystems. Results were normalized to $\beta$-microglobulin. Relative gene expression was calculated using the $\triangle \Delta C T$ method (58).

ELISA from BALF and plasma. ELISA kits were used for TGF- $\beta 1$, human VEGF (R\&D Systems), and rat albumin (GenWay).

IHC. Transversal left sections $(3 \mu \mathrm{m})$ were deparaffinized and rehydrated. After blocking endogenous peroxidase (methanol $/ \mathrm{H}_{2} \mathrm{O}_{2}$ ), antigen retrieval was performed: $0.01 \mathrm{M}$ citrate buffer ( $\mathrm{pH}$ 6.0) for 20 minutes (caspase-3, cleaved caspase-3, CD34, PEDF and VEGF), for 45 minutes (P-Smad2), and for 1 hour (CD31). Sections were blocked with $1 \%$ normal swine serum in TBS, then incubated with primary antibody $4{ }^{\circ} \mathrm{C}$ overnight (Table 3 ). The secondary biotin-conjugated antibody was applied for 1 hour at room temperature, followed by streptavidin/HRP solution (Dako) at 1:600. Sections were developed in 3,3'-diaminobenzidine (DAB) chromogen substrate (Sigma-Aldrich) and counterstained with Mayer's hematoxylin.

For immunofluorescence, slides were steamed for 20 minutes, except for those slides containing samples stained for P-Smad2, P-Smad2/VEGF, and P-Smad2/CD34, which were steamed for 45 minutes. For PEDF/collagen-1, enzymatic digestion was performed instead (proteinase K 1:50; Dako). After blocking for 15 minutes with $1 \%$ normal swine serum/TBS, sections were incubated with primary antibody no. 1 overnight at $4{ }^{\circ} \mathrm{C}$, followed by fluorescence-conjugated secondary antibody no. 1 for 2 hours at room temperature. Sections were incubated with primary antibody no. 2 followed by fluorescence-conjugated secondary antibody no. 2, both for 2 hours at room temperature. Slides were mounted using VECTASHIELD with DAPI (Vector Laboratories). Details are shown in Table 3. Negative controls with nonspecific Ig were run in parallel.

The In Situ Cell Death Detection kit, TMR red (Roche Applied Science) was used for TUNEL/CD31 and TUNEL/CD34. Heat-induced retrieval (citrate buffer) was performed prior to TUNEL, followed by indirect labeling with anti-CD31 or anti-CD34 and anti-goat FITC antibody. Positive (DNAse-treated section) and negative controls (terminal transferase omitted) were run in parallel.

Quantification of immunostainings. Four transversal sections were used for quantitative IHC. Fifteen to twenty images were taken $(\times 400)$ showing parenchyma without large airways or vessels: Approximately $70 \%$ of acquisitions were randomly selected from fibrotic and $30 \%$ from nonfibrotic areas, and code numbers were assigned. Images were scored according to Ashcroft (55). Quantification of picture sets was performed by 2 blinded investigators. Computer-based analyses were done with ImageJ.

VEGF and PEDF were scored with a modified scoring system according to Reiner et al. (59): staining intensity was scored as $0,1,2$, or 3 , with 0 indicating no staining, 1 indicating weakest staining, 2 indicating moderate staining, and 3 indicating most intense staining. Positive cells and tissue were scored as follows: $0,0 \% ; 1,<10 \% ; 2,<50 \% ; 3,<90 \%$; and $4,90 \%-100 \%$. Values for staining intensity and positive cells/tissue were added, and total results ranged from 0 (no staining, no cells/tissue stained) to 7 (maximal staining in $>90 \%$ of cells or tissue). Airways and vessels with ED greater 
than $25 \mu \mathrm{m}$ were excluded. For vascular density, images of CD31 or CD34 IHC underwent color deconvolution to obtain vascular area from $\mathrm{DAB}^{+}$ area by thresholding (60). Total tissue area was calculated from original images by thresholding and binarization. Vascular density was presented as percentage of vascular versus total tissue area.

For quantification of P-Smad2 in PA VSMC and caspase- 3 or cleaved caspase-3 in PA ECs, images of 20-30 PA were taken for each animal: ED of PA was measured, and Ashcroft score was assigned for surrounding tissue. Positive and total cell numbers were counted manually. Results were expressed as percentage of positive cells.

For nuclear P-Smad2 analysis, 20-30 regions/animal were acquired $(\times 400$, red/blue channel and phase contrast pictures each, large vessels or airways omitted). $70 \%$ of images were collected from fibrotic and $30 \%$ from nonfibrotic regions and coded. Nuclei stained by P-Smad2 and DAPI were detected by colocalization highlighter plug-in for ImageJ and were counted by automated particle counting after watershed discrimination. Values are expressed as percentage of positive nuclei. A composite image of red (P-Smad2), blue (DAPI), and phase contrast image was used to assign fibrotic scores to each picture.

For caspase-3/CD31, caspase-3/CD34, TUNEL/CD31, TUNEL/CD34 and P-VEGFR2/CD34, 20-30 areas were acquired per animal, similar to nuclear P-Smad2. Fibrotic scores were assigned. Double-positive cells were counted. Histomorphologic criteria were used to select $\mathrm{CD} 31^{+}$or $\mathrm{CD} 34^{+}$ EC. The number of double-positive cells per field was divided by total $\mathrm{CD} 31^{+}$or $\mathrm{CD} 34^{+}$area (green) to normalize for vascularization differences. Values are given as double-positive cells $/ \mathrm{mm}^{2} \mathrm{CD} 31^{+}$or $\mathrm{CD} 34^{+}$area.

Confocal microscopy. To verify apoptotic (caspase- $\left.3^{+} / \mathrm{TUNEL}^{+}\right)$EC $\left(\mathrm{CD} 31^{+} /\right.$ $\left.\mathrm{CD} 34^{+}\right)$, confocal microscopy was performed on sections adjacent to the ones used for immunofluorescence (MP Leica TCS SP5 laser scanning confocal system). Z-stacks of optical sections with z-distance $0.2 \mu \mathrm{m}$ were acquired with red, green and blue color filters. Image stacks were taken at $\times 630$ magnification. Processing and reslicing of image stacks was done in ImageJ.

Cell culture. Primary lung fibroblasts were isolated as described before from patients undergoing cancer surgery (61). Patients gave written consent, and the study was approved by the Ethics Board. St. Joseph's Healthcare. Fibroblasts were cultured in RPMI 1640 with 10\% FBS, $100 \mathrm{IU} / \mathrm{ml}$ penicillin, and $100 \mu \mathrm{g} / \mathrm{ml}$ streptomycin (Invitrogen). $2 \times 10^{4}$ cells between passages 3 and 6 were seeded in 6 -well plates and rendered serum free for 24 hours. Recombinant human TGF- $\beta 1$ and VEGF (165 amino acid isoform; R\&D Systems) were added for 24-hour stimulation, and protein lysate was prepared.

Western blotting. $20 \mu \mathrm{g}$ protein was loaded for SDS-PAGE. Proteins were blotted onto a nitrocellulose membrane, blocked 1 hour in 5\% dry milk/ TBS-0.1\% Tween 20, and incubated with primary antibodies (collagen-1, $\alpha$-SMA, P-Smad2, $\alpha$-tubulin) overnight at $4{ }^{\circ} \mathrm{C}$. Secondary HRP-conjugated antibodies were applied for 1 hour at room temperature. For detailed information regarding antibodies, see Table 3. Blots were developed with ECL reagent on Hyperfilm x-ray films (Amersham Biosciences) and scanned; densitometry was done with Quantity One (Bio-Rad).

Immunofluorescence of fibroblasts. Fibroblasts were grown to subconfluence in chamber slides (Nunc), fixed in 10\% formalin (10 min), and permeabilized with $0.5 \%$ Triton X-100 (Sigma-Aldrich) for 10 minutes for collagen-1 and vimentin. After blocking (1\% BSA/PBS, $1 \mathrm{~h}$ ), cells were incubated with primary antibodies (CD31, CD45, collagen-1, E-cadherin, and vimentin) for 2 hours, followed by fluorescence-conjugated secondary antibody for 1 hour. Negative controls were run in parallel with nonspecific Ig. Images were taken at $\times 400$ magnification with AxioCam MRm and AxioVision 3.1 software (Zeiss).

Statistics. Data are presented as mean \pm SEM. Two groups were compared with 2-tailed unpaired Student's $t$ test and more than 2 groups with 1-way ANOVA followed by Neuman-Keuls multiple comparison test. Spearman's rank correlation was used for correlation analysis. Statistical tests and graphs were done with GraphPad Prism 5.0 (GraphPad Software). $P<0.05$ was considered significant.

\section{Acknowledgments}

The authors acknowledge Fernando Pitossi (Campomar Foundation, Buenos Aires, Argentina) and Daniel Anthony (University of Southampton, Southampton, United Kingdom) for the construction of AdVEGF. They also thank Russ Ellis, Jennifer Wattie, Fuqin Duan, Limin Liu, Mary Jo Smith, and Jane Ann Smith for their outstanding technical help. The work was funded by the Canadian Institute for Health Research (CIHR), an unrestricted grant by GlaxoSmithKline Canada, and a generous personal donation of Hans-Benno and Silvie Ulbrich, Würzburg, Germany. L. Farkas is recipient of a Research Fellowship from the DFG (FA 841/2-1). P. Margetts has a Clinician Scientist Award from the CIHR. M. Kolb has a Career Development Award from the Department of Medicine at McMaster University and a New Investigator Award from CIHR.

Received for publication August 14, 2008, and accepted in revised form February 18, 2009.

Address correspondence to: Martin Kolb, Departments of Medicine, Pathology, and Molecular Medicine, McMaster University, Firestone Institute for Respiratory Health, 50 Charlton Ave. East, Room T2121, Hamilton, Ontario L8N 4A6, Canada. Phone: (905) 522-1155 ext. 34973; Fax: (905) 521-6183; E-mail: kolbm@mcmaster.ca.
1. Ryu, J.H., Colby, T.V., and Hartman, T.E. 1998. Idiopathic pulmonary fibrosis: current concepts. Mayo Clin. Proc. 73:1085-1101.

2. [No authors listed]. 2000. American Thoracic Society. Idiopathic pulmonary fibrosis: diagnosis and treatment. International consensus statement. American Thoracic Society (ATS), and the European Respiratory Society (ERS). Am. J. Respir. Crit. Care Med. 161:646-664.

3. Gross, T.J., and Hunninghake, G.W. 2001. Idiopathic pulmonary fibrosis. N. Engl. J. Med. 345:517-525.

4. Nathan, S.D., Noble, P.W., and Tuder, R.M. 2007. Idiopathic pulmonary fibrosis and pulmonary hypertension: connecting the dots. Am. J. Respir. Crit. Care Med. 175:875-880.

5. Weitzenblum, E., Ehrhart, M., Rasaholinjanahary, J., and Hirth, C. 1983. Pulmonary hemodynamics in idiopathic pulmonary fibrosis and other inter- stitial pulmonary diseases. Respiration. 44:118-127. 6. Patel, N.M., Lederer, D.J., Borczuk, A.C., and Kawut, S.M. 2007. Pulmonary hypertension in idiopathic pulmonary fibrosis. Chest. 132:998-1006.

7. Nadrous, H.F., et al. 2005. The impact of pulmonary hypertension on survival in patients with idiopathic pulmonary fibrosis. Chest. 128:616S-617S.

8. Lettieri, C.J., Nathan, S.D., Barnett, S.D., Ahmad, S., and Shorr, A.F. 2006. Prevalence and outcomes of pulmonary arterial hypertension in advanced idiopathic pulmonary fibrosis. Chest. 129:746-752.

9. Strange, C., and Highland, K.B. 2005. Pulmonary hypertension in interstitial lung disease. Curr. Opin. Pulm. Med. 11:452-455.

10. Ebina, M., et al. 2004. Heterogeneous increase in CD34-positive alveolar capillaries in idiopathic pulmonary fibrosis. Am. J. Respir. Crit. Care Med. 169:1203-1208.
11. Cosgrove, G.P., et al. 2004. Pigment epitheliumderived factor in idiopathic pulmonary fibrosis: a role in aberrant angiogenesis. Am. J. Respir. Crit. Care Med. 170:242-251.

12. Simler, N.R., et al. 2004. Angiogenic cytokines in patients with idiopathic interstitial pneumonia. Thorax. 59:581-585.

13. Chaudhary, N.I., et al. 2007. Inhibition of PDGF, VEGF and FGF signalling attenuates fibrosis. Eur. Respir. J. 29:976-985.

14. Hamada, N., et al. 2005. Anti-vascular endothelial growth factor gene therapy attenuates lung injury and fibrosis in mice. J. Immunol. 175:1224-1231.

15. Motomura, Y., et al. 2005. The gene transfer of soluble VEGF type I receptor (Flt-1) attenuates peritoneal fibrosis formation in mice but not soluble TGF-beta type II receptor gene transfer. Am. J. Physiol. Gastrointest. Liver Physiol. 288:G143-G150. 
16. Voelkel, N.F., Vandivier, R.W., and Tuder, R.M. 2006. Vascular endothelial growth factor in the lung. Am. J. Physiol. Lung Cell Mol. Physiol. 290:L209-L221.

17. Ramirez-Bergeron, D.L., Runge, A., Adelman, D.M. Gohil, M., and Simon, M.C. 2006. HIF-dependent hematopoietic factors regulate the development of the embryonic vasculature. Dev. Cell. 11:81-92.

18. Schofield, C.J., and Ratcliffe, P.J. 2004. Oxygen sensing by HIF hydroxylases. Nat. Rev. Mol. Cell Biol. 5:343-354

19. Cai, J., Jiang, W.G., Grant, M.B., and Boulton, M. 2006. Pigment epithelium-derived factor inhibits angiogenesis via regulated intracellular proteolysis of vascular endothelial growth factor receptor 1 . J. Biol. Chem. 281:3604-3613.

20. Zhang, S.X., Wang, J.J., Gao, G., Parke, K., and Ma, J.X. 2006. Pigment epithelium-derived factor downregulates vascular endothelial growth factor (VEGF) expression and inhibits VEGF-VEGF receptor 2 binding in diabetic retinopathy. J. Mol. Endocrinol. 37:1-12

21. Sime, P.J., Xing, Z., Graham, F.L., Csaky, K.G., and Gauldie, J. 1997. Adenovector-mediated gene transfer of active transforming growth factor-beta 1 induces prolonged severe fibrosis in rat lung. J. Clin. Invest. 100:768-776.

22. Bonniaud, P., et al. 2003. Adenoviral gene transfer of connective tissue growth factor in the lung induces transient fibrosis. Am. J. Respir. Crit. Care Med. 168:770-778.

23. Bonniaud, P., et al. 2005. Progressive transforming growth factor beta1-induced lung fibrosis is blocked by an orally active ALK5 kinase inhibitor. Am. J. Respir. Crit. Care Med. 171:889-898.

24. Moeller, A., Ask, K., Warburton, D., Gauldie, J., and Kolb, M. 2008. The bleomycin animal model: A useful tool to investigate treatment options for idiopathic pulmonary fibrosis? Int. J. Biochem. Cell. Biol. 40:362-382.

25. Parra, E.R., et al. 2005. Heterogeneous remodeling of lung vessels in idiopathic pulmonary fibrosis Lung. 183:291-300.

26. Zaiman, A.L., et al. 2008. Role of the TGF-\{beta\}/ Alk5 Signaling Pathway in Monocrotaline-induced Pulmonary Hypertension. Am. J. Respir. Crit. Care Med. 177:896-905.

27. Sturrock, A., et al. 2006. Transforming growth factor-beta 1 induces $\mathrm{Nox} 4 \mathrm{NAD}(\mathrm{P}) \mathrm{H}$ oxidase and reactive oxygen species-dependent proliferation in human pulmonary artery smooth muscle cells. Am. J. Physiol. Lung Cell Mol. Physiol. 290:L661-L673.

28. Koli, K., et al. 2006. Bone morphogenetic protein4 inhibitor gremlin is overexpressed in idiopathic pulmonary fibrosis. Am. J. Pathol. 169:61-71.

29. Budhiraja, R., Tuder, R.M., and Hassoun, P.M. 2004. Endothelial dysfunction in pulmonary hypertension. Circulation. 109:159-165.

30. Jeffery, T.K., and Morrell, N.W. 2002. Molecular and cellular basis of pulmonary vascular remodeling in pulmonary hypertension. Prog. Cardiovasc. Dis. 45:173-202.
31. Richter, A., et al. 2004. Impaired transforming growth factor-beta signaling in idiopathic pulmonary arterial hypertension. Am. J. Respir. Crit. Care Med. 170:1340-1348.

32. Renzoni, E.A., et al. 2003. Interstitial vascularity in fibrosing alveolitis. Am. J. Respir. Crit. Care Med. 167:438-443.

33. Pollman, M.J., Naumovski, L., and Gibbons, G.H. 1999. Vascular cell apoptosis: cell type-specific modulation by transforming growth factor- $\beta 1$ in endothelial cells versus smooth muscle cells. Circulation. 99:2019-2026.

34. Sakao, S., Taraseviciene-Stewart, L., Wood, K., Cool C.D., and Voelkel, N.F. 2006. Apoptosis of pulmonary microvascular endothelial cells stimulates vascular smooth muscle cell growth. Am. J. Physiol. Lung Cell Mol. Physiol. 291:L362-L368.

35. Traweek, S.T., Kandalaft, P.L., Mehta, P., and Battifora, H. 1991. The human hematopoietic progenitor cell antigen (CD34) in vascular neoplasia. Am. J. Clin. Pathol. 96:25-31.

36. Gomperts, B.N., and Strieter, R.M. 2007. Fibrocytes in lung disease. J. Lenkoc. Biol. 82:449-456.

37. Schraufnagel, D.E., Mehta, D., Harshbarger, R., Treviranus, K., and Wang, N.S. 1986. Capillary remodeling in bleomycin-induced pulmonary fibrosis. Am. J. Pathol. 125:97-106.

38. Voelkel, N.F., Hoeper, M., Maloney, J., and Tuder, R.M. 1996. Vascular endothelial growth factor in pulmonary hypertension. Ann. N. Y. Acad. Sci. 796:186-193.

39. Lappi-Blanco, E., Soini, Y., Kinnula, V., and Paakko, P. 2002. VEGF and bFGF are highly expressed in intraluminal fibromyxoid lesions in bronchiolitis obliterans organizing pneumonia. J. Pathol. 196:220-227.

40. Tzouvelekis, A., et al. 2007. Comparative expression profiling in pulmonary fibrosis suggests a role of hypoxia-inducible factor-1alpha in disease pathogenesis. Am. J. Respir. Crit. Care Med. 176:1108-1119.

41. Meyer, C., Notari, L., and Becerra, S.P. 2002. Mapping the type I collagen-binding site on pigment epithelium-derived factor. Implications for its antiangiogenic activity. J. Biol. Chem. 277:45400-45407.

42. Ho, T.C., et al. 2007. PEDF induces p53-mediated apoptosis through PPAR gamma signaling in human umbilical vein endothelial cells. Cardiovasc. Res. 76:213-223.

43. Kasahara, Y., et al. 2000. Inhibition of VEGF receptors causes lung cell apoptosis and emphysema. J. Clin. Invest. 106:1311-1319.

44. Taraseviciene-Stewart, L., et al. 2001. Inhibition of the VEGF receptor 2 combined with chronic hypoxia causes cell death-dependent pulmonary endothelial cell proliferation and severe pulmonary hypertension. FASEB J. 15:427-438.

45. Pertovaara, L., et al. 1994. Vascular endothelial growth factor is induced in response to transforming growth factor-beta in fibroblastic and epithelial cells. J. Biol. Chem. 269:6271-6274.

46. Zeng, X., Gray, M., Stahlman, M.T., and Whitsett, J.A. 2001. TGF-beta1 perturbs vascular develop- ment and inhibits epithelial differentiation in fetal lung in vivo. Dev. Dyn. 221:289-301.

47. Margetts, P.J., et al. 2001. Gene transfer of transforming growth factor-beta 1 to the rat peritoneum: effects on membrane function. J. Am. Soc. Nephrol. 12:2029-2039.

48. Renzoni, E.A. 2004. Neovascularization in idiopathic pulmonary fibrosis: too much or too little? Am. J. Respir. Crit. Care Med. 169:1179-1180.

49. Campbell, A.I., Zhao, Y., Sandhu, R., and Stewart, D.J. 2001. Cell-based gene transfer of vascular endothelial growth factor attenuates monocrotaline-induced pulmonary hypertension. Circulation. 104:2242-2248

50. Zhao, Y.D., et al. 2006. Microvascular regeneration in established pulmonary hypertension by angiogenic gene transfer. Am. J. Respir. Cell Mol. Biol. 35:182-189.

51. Partovian, C., et al. 2000. Adenovirus-mediated lung vascular endothelial growth factor overexpression protects against hypoxic pulmonary hypertension in rats. Am. J. Respir. Cell Mol. Biol. 23:762-771.

52. Gong, F., et al. 2005. Gene transfer of vascular endothelial growth factor reduces bleomycininduced pulmonary hypertension in immature rabbits. Pediatr. Int. 47:242-247.

53. Strieter, R.M., Gomperts, B.N., and Keane, M.P. 2007. The role of CXC chemokines in pulmonary fibrosis. J. Clin. Invest. 117:549-556.

54. Bett, A.J., Haddara, W., Prevec, L., and Graham, F.L. 1994. An efficient and flexible system for construction of adenovirus vectors with insertions or deletions in early regions 1 and 3. Proc. Natl. Acad. Sci. U. S. A. 91:8802-8806.

55. Ashcroft, T., Simpson, J.M., and Timbrell, V. 1988. Simple method of estimating severity of pulmonary fibrosis on a numerical scale. J. Clin. Pathol. 41:467-470.

56. Abramoff, M.D., Magelhaes, P.J., and Ram, S.J. 2004. Image processing with ImageJ. Biophotonics International. 11:36-42.

57. Kolb, M., Margetts, P.J., Sime, P.J., and Gauldie, J. 2001. Proteoglycans decorin and biglycan differentially modulate TGF-\{beta\}-mediated fibrotic responses in the lung. Am. J. Physiol. Lung Cell Mol. Pbysiol. 280:L1327-L1334.

58. Applied Biosystems. 1997. Relative quantitation of gene expression: ABI PRISM 7700 Sequence Detection System. User Bulletin \#2. Rev B. Applied Biosystems, Foster City, California, USA.

59. Reiner, A., et al. 1990. Immunocytochemical localization of estrogen and progesterone receptor and prognosis in human primary breast cancer. Cancer Res. 50:7057-7061.

60. Ruifrok, A.C., and Johnston, D.A. 2001. Quantification of histochemical staining by color deconvolution. Anal. Quant. Cytol. Histol. 23:291-299.

61. Jordana, M., et al. 1988. Heterogeneous proliferative characteristics of human adult lung fibroblast lines and clonally derived fibroblasts from control and fibrotic tissue. Am. Rev. Respir. Dis. 137:579-584. 